\title{
The Supplemental Security Income Program
}

\author{
Mary C. Daly \\ Federal Reserve Bank of San Francisco \\ 101 Market Street, Mail Stop 1130 \\ San Francisco, CA 94105 \\ (415) 974-3186 \\ mary.daly@sf.frb.org \\ Richard V. Burkhauser \\ Cornell University \\ Department of Policy Analysis and Management \\ N134 Martha Van Rensselaer Hall \\ Ithaca, NY 14853 \\ (607) 255-2097 \\ rvb1@cornell.edu
}

September 2000

We thank Robert Moffitt, Kathleen McGarry, Kalman Rupp, David Wittenburg, and participants at the NBER Conference on Means-Tested Transfer Programs for helpful comments. We thank Andrew Houtenville, Robert Weathers, and David Wittenburg for providing data and Carol D'Souza and Heather Royer for research assistance. We also are grateful to Anita Todd and Rochelle Frank for editorial assistance, and to Florence Allen for helping compile the document. The opinions expressed in this paper do not necessarily reflect the views of the Federal Reserve Bank of San Francisco. 


\section{The Supplemental Security Income Program}

\section{Introduction}

Supplemental Security Income (SSI) is a nationwide federal assistance program for aged, blind, and disabled individuals with low incomes. SSI was enacted in 1972 and began paying benefits in 1974, replacing a patchwork of state-run programs entitlement programs created under the Social Security Act of 1935 and its Amendments in 1950. SSI began as a relatively small program providing benefits to a largely elderly population. Since that time SSI has grown to become the largest federal means-tested cash assistance program in the U.S., with a caseload dominated by children and working-age adults with disabilities. In 1999, an average of 6.3 million people-the vast majority under age 65-received SSI benefits and federal and state expenditures totaled $\$ 34$ billion.

Rapid program growth and the changing composition of SSI beneficiaries, as well as recent efforts to devolve fiscal and administrative responsibility for social programs from the federal to the state governments and to integrate a variety of traditional "non-workers" into the labor market all have raised questions about the role that SSI plays in the broader United States social welfare system. The establishment of SSI was the culmination of a four-year debate over a more overarching welfare reform proposal — the Family Assistance Plan (FAP) — intended to extend the federal social safety net to all low income Americans. While Congress eventually rejected the universality of FAP, it passed SSI, a categorical welfare program based on the same negative income tax principles as FAP but targeted on a subset of low-income individuals not expected to work - the aged, blind, and disabled. SSI passed when FAP did not largely because Congress believed that providing guaranteed income assistance to individuals not expected to work was likely to have a much smaller negative impact on work than a universal negative income tax program.

In 1972, those not expected to work included individuals aged 65 and older, the blind, and people with disabilities. While these categories were always somewhat arbitrary and difficult to establish and 
assess - particularly with regard to disability—since 1972, social expectations regarding who should work and who should be entitled to income transfers have changed dramatically. These changes have renewed the debate over what populations a program like SSI should serve. On the one hand, individuals are living and working longer and the Americans with Disabilities Act (ADA) has granted people with disabilities a legal right to equal access to employment, suggesting that the aged, blind, and disabled may be better able to work than in the past. On the other hand, the normal retirement age for Social Security benefits is increasing, welfare reforms have placed limits on the number of years single mothers with children may receive benefits in lieu of working, and poverty rates among children remain high despite a long and robust economic expansion, suggesting that income maintenance programs like SSI will remain an important component of the social safety net. All these factors will impact on the politically determined boundaries of the only remaining federal cash-based means-tested entitlement program without time limits available to both adults and children.

In this chapter we provide the basic information necessary for SSI policy makers to make informed choices about its future. We present a description of SSI, discuss the original rationale for the program and examine the cultural and political factors that have affected its mission over time. We then summarize the economic issues raised by the existence and structure of the program, review the empirical evidence on the behavioral effects of SSI, and discuss current policy issues and areas of future research. In Section II we review the program's history and describe the structure and evolution of program rules. In Section III we provide expenditure, caseload, and program recipient statistics. In Section IV, we summarize the primary economic issues related to the SSI program, and in Section V we review the empirical evidence regarding these issues. In Section VI we discuss current policy issues surrounding SSI and discuss likely future policy concerns. We summarize our findings in Section VII. 


\section{History and Structure of the SSI Program}

The Supplemental Security Income program is a nationwide Federal assistance program administered by the Social Security Administration (SSA), which pays cash benefits to low-income individuals who are 65 years of age or older or who are blind or disabled. SSI was enacted in 1972 and began paying benefits in 1974 replacing the state Old-Age Assistance, Aid to the Permanently and Totally Disabled, and Aid to the Blind Programs created by the Social Security Act of 1935 and its amendments in 1950. In this section we review the history of the SSI program, describe current program structure, eligibility criteria, and benefit levels, and discuss how the program's goals and rules have evolved over time.

\section{Original Rationale and Program Goals}

The establishment of a federal income maintenance program for the aged, blind, and disabled —SSI—was the culmination of a four-year debate that began with a more overarching welfare reform proposal—the Family Assistance Plan (FAP)—proposed by President Nixon on August 8, $1969 .{ }^{1}$ FAP was the first serious attempt to institute a federal negative income tax program equivalent to those proposed by Stigler (1946), Friedman $(1962,1968)$, and Tobin (1968). FAP departed from existing welfare policy in three important ways: (1) it was universal rather than categorical, with low income and assets as the only eligibility criteria; (2) it was run through the federal tax system rather than administered by state and local governments; and (3) it had a low benefit reduction rate, in keeping with the notion that low tax rates provide desirable work incentives. ${ }^{2}$

${ }^{1}$ See Burke and Burke (1974) and Smeeding (1994) for a more detailed historical discussion of how SSI became the nation's first negative income tax program.

${ }^{2}$ The key features of most NIT proposals are universality, federal benefit administration, and low benefit reduction rates. For a fuller discussion of the origins of NIT policy see Burkhauser and Finegan (1989, 1993). 
Congress eventually rejected the idea of an income maintenance program for all Americans with low income, but on October 17, 1972 created the Supplemental Security Income program, a categorical welfare program targeted on the subset of the poor who were aged, blind, or disabled. SSI passed when FAP did not largely because Congress believed that providing income assistance to needy individuals not expected to work was likely to have a much smaller negative impact on employment than a universal negative income tax program. In 1972, those not expected to work included individuals age 65 and older, the blind, and people with disabilities, subgroups of the population that already were targets of statebased assistance programs.

In keeping with some of the themes of FAP, the new SSI program federalized benefit administration, set minimum benefit standards, imposed uniform eligibility criteria, and set low benefit reduction rates on labor earnings. Legislative records suggest that SSI was intended to reduce variability in the types of individuals allowed onto the rolls and in the amount of assistance they received, to make economic resources the only determinant of eligibility for those meeting the categorical requirements, and to provide beneficiaries incentives to work to supplement their income and move towards rehabilitation (U.S. House Committee on Ways and Means, 1971). ${ }^{3,4}$ Thus, under SSI, Congress federalized benefit administration, set minimum benefit standards, imposed uniform eligibility criteria, and set relatively low benefit reduction rates on labor earnings. In addition to adopting some of the administrative mechanisms of FAP, the SSI program began to blur the traditional ability-to-work standard for determining who should be entitled to public welfare payments. By extending SSI benefits

${ }^{3}$ Most legislative models of the NIT, including FAP and SSI, impose both an income and asset test. Throughout this chapter we refer to income and assets as economic resources.

${ }^{4}$ Under the former state-run programs the amount of assistance could vary from recipient to recipient according to an individual's assessed needs, age, and living situation. 
to the needy families of children with disabilities, Congress expanded the social safety net to include families headed by adults who were "employable". 5,6

Although the goals of the SSI disability program have not changed since its inception in 1974, its structure has been subject to numerous legislative, administrative, and court actions. Table 1 provides a history of the major federal SSI legislation. These actions primarily have focused on making the disability criteria more target effective and on enhancing incentives aimed at returning recipients to the workforce. For the child disability component of the program, changes have focused on providing an appropriate vocational criteria for children that does not unduly discourage rehabilitation and school success. Notably, there have been few changes to the means test criteria and no adjustment for inflation in these criteria, meaning that over time, the income threshold for eligibility has fallen in real terms. Finally, other legislative efforts have centered on limiting the eligibility of non-citizens. The legislative history of SSI shows that the primary mechanisms used by policymakers to alter the coverage and the generosity of SSI have been changes in the categorical eligibility criteria, rather than changes in the size of SSI benefits.

\section{SSI Eligibility Criteria}

SSI eligibility is a function of three program-based categorical criteria-age, disability, or blindness - as well as more general requirements associated with income and asset limits, and citizenship and residency rules. Figure 1 provides a summary of the application process for SSI benefits. Citizens and residents qualifying for SSI on categorical grounds are next required to meet the income and asset tests. Qualifying individuals who do not meet the means test may maintain their categorical eligibility

${ }^{5}$ Poor children with disabilities had previously been included in state AFDC programs.

${ }^{6}$ A final category of people allowed onto the SSI rolls, despite their potential to find alternative private support, were noncitizens. By law, legal immigrants had to show income sponsorship before immigrating to the United States. Largely due to the definition of income in the SSI means test, the 1972 legislation allowed sponsored immigrants who were poor to apply for SSI. This primarily affected the SSI aged program. 
for up to 12 months. The Social Security Administration is responsible for screening applicants and making awards for SSI. Table 2 lists the criteria used to determine eligibility for SSI benefits in 1999.

Categorical Eligibility Criteria. Individuals with limited income and assets may qualify for SSI benefits based on three categorical criteria: age, blindness, or disability. Applicants need only meet one of the three criteria, although some applicants fit multiple categories. The categorical program requirements for the aged and the blind are straightforward. Individuals are categorically eligible for SSI based on age if they are age 65 or older. Individuals may receive SSI benefits for the blind if they have 20/200 vision or less with the use of a correcting lens in their better eye, or if they have tunnel vision of 20 degrees or less. These objective standards make for relatively easy and uniform screening of aged and blind SSI applicants at offices of the Social Security Administration across the United States. ${ }^{7}$

In contrast, the disability screening process is more complex. First, there is no simple definition of disability. ${ }^{8}$ The most common measures of disability in the economics literature are built on a methodology developed by Nagi $(1965,1969 a, b, 1991)$ that distinguishes three components of disability. The first component is the presence of a pathology—a physical or mental malfunction, or the interruption of a normal process, or both. This leads to a second component, an impairment, which Nagi defines as a physiological, anatomical, or mental loss or abnormality that limits a person's capacity and level of function. The final component of disability is defined as an inability to perform, or a limitation in

\footnotetext{
${ }^{7}$ Although the measurement of these "objective standards" is relatively straightforward, the justification for using them as standards for "inability to work" is less so. A literature exists which argues that categorical age is not a useful measure of ability to work. A parallel literature exists which suggests that functional ability rather than medical conditions are superior criteria for determining "ability to work" (Library of Congress 1998; National Research Council 2000).

${ }^{8}$ Mashaw and Reno (1996) argue that the appropriateness of any definition of disability depends on the purpose for which it is used. They document over 20 definitions of disability used for purposes of entitlement to public or private income transfers, government services, or statistical analysis. In the Americans with Disabilities Act of 1990 (ADA), disability is defined as a physical or mental impairment that substantially limits one or more major life activities, a record of such an impairment, or being regarded as having such an impairment. LaPlante (1991) provides a useful discussion of alternative definitions that can be used to estimate this population.
} 
performing, socially expected roles and tasks. For men and, increasingly, for women of working age, market work is a socially expected role. Hence, those who are unable to perform or are limited in their ability to work are considered disabled.

The disability determination process for SSI incorporates some of the reasoning put forth in Nagi's disability definition. Applicants for disability benefits move through a multi-step process in which their pathology, impairment, and level of functioning are judged. Applicants thought to be unable to engage in any substantial work become eligible for benefits. Below we describe the process of disability determination for both adults and children applying for SSI disability benefits.

Like the aged and blind, persons seeking disability benefits also apply at an office of the Social Security Administration. Once the federal officials and the applicant have gathered sufficient information to complete the application, it is submitted to a state agency for determination of disability. State disability examiners, working with vocational and medical consultants, act as the primary gatekeepers of both SSI and Social Security Disability Insurance (SSDI). ${ }^{9}$ Disability decisions are made by state agencies, acting under contract to the federal government. Therefore, although disability eligibility criteria are uniform across the country, the interpretation of these criteria, and hence the disability determination process itself, can and does systematically vary from state to state and over time. Table 3 shows differences in mean allowance rates (initial acceptances to initial applications), by state between 1974 and 1993. As the table indicates, mean allowance rates vary considerably across states, ranging from lows of 28 in Louisiana and New Mexico to highs of 48 in Delaware, New Jersey, and Rhode Island.

${ }^{9} \mathrm{SSDI}$ is a social insurance program that provides payments to individuals who have paid social security taxes for the appropriate number of quarters and who are judged to be disabled under the SSA guidelines. Unlike SSI it is not means-tested. However, it does have restrictions on labor earnings consistent with its criteria for disability eligibility. See Bound and Burkhauser (1999) for a fuller discussion of this program from an economic perspective. 
Disability Screening for Adults. SSA defines adult disability as the inability to engage in substantial gainful activity by reason of a medically determinable physical or mental impairment that is expected to result in death or last at least 12 months. Applicants must be unable to do any work that exists in the national economy for which they are qualified by virtue of age, education, and work experience. The United States does not award federal disability benefits for partial disability. ${ }^{10}$

As a practical matter, SSA asks the state disability determination offices to follow a five-step procedure in their initial disability determination. ${ }^{11}$ First, the examiners check to see if applicants are currently working and making more than the "substantial gainful activity" (SGA) amount—\$700 a month in 1999. If so, their application is denied. As can be seen in Figure 2, almost no cases are rejected in this manner, since presumably the SSA field offices have already checked to see if applicants are working before they send applications to the disability determination office. ${ }^{12}$ Second, the state disability examiners determine if the applicant has a severe impairment that is expected to last 12 months or result in death. If not, the application is denied. About $26(18+8)$ percent of all applicants were denied at this step in 1994. Third, the state disability examiners look to see if the impairment meets the medical listings. If the impairment is listed, applicants pass the categorical screening for disability. If the impairment is judged to be equivalent to one of the medical listings then applicants also meet the categorical requirement for benefits. Most recipients who pass the disability screening do so at this stage

${ }^{10}$ However, as will be shown later, in some instances the SSI program allows individuals with disabilities to exceed the earnings limit and continue to receive SSI benefits, making it a type of partial disability insurance. Most other western industrialized countries provide partial disability benefits to their working-age populations. For a discussion of disability program rules in other western industrialized nations see Aarts, Burkhauser, and DeJong (1996).

${ }^{11}$ Our discussion of the adult disability determination process draws heavily on Bound and Burkhauser (1999).

${ }^{12}$ The percentages denied in Figure 2 are based on outcomes from initial SSDI applications, the data available from published sources. However, there is no reason to believe that the patterns for SSI would be significantly different. 
because their impairment either "meets" or "equals" one on the medical listing ( 21 percent of all applicants were approved at this step in 1994).

Fourth, if a decision cannot be reached on medical factors alone, applicants are evaluated in terms of residual functional capacity. If they are found to be able to meet the demands of "past relevant work" their claim is denied (20 percent of all applicants were denied at this step in 1994). If individuals are deemed unable to do past relevant work, examiners determine if the impairment prevents the applicant from doing any other work. Here vocational factors are considered. If, for example, applicants' maximum sustained work capacity is limited to sedentary work and they are at least age 50 to 54, with less than a high school education and no skilled work experience, then they would be considered disabled and pass the categorical screening. In contrast, if applicants' previous employment experience includes skilled work, then they would not receive benefits. At this stage, 11 percent of all applicants were determined eligible for benefits and 22 percent were denied benefits in 1994.

Applicants who are denied benefits can ask for a reconsideration. Their file will then be reviewed by a second team of examiners. If they are rejected after reconsideration, individuals may appeal the case to an administrative law judge. It is at this stage that applicants will for the first time come face-to-face with a gatekeeper. Individuals denied benefits at this stage may appeal the decision to the Social Security Appeals Council and then to the District Courts. A substantial minority of appealed claims get past the initial hearing (33 percent in 1996), with a smaller portion getting as far as an administrative law judge (23 percent in 1995) (U.S. House of Representatives 1998). ${ }^{13}$ For the claimants who are either allowed benefits at the initial level or who don't appeal, the application and decision process usually takes a few months. For those who appeal to the administrative law judge, the process can take a year or more.

\footnotetext{
${ }^{13}$ There is some evidence that the proportion of claimants who appeal and the proportion of decisions that get reversed rise and fall with the percentage of initial denials (Lando, Cutler, and Gamber 1982).
} 
Disability Screening for Children. Screening children for disability eligibility has proven to be more complex and contentious than adult disability screening. When the SSI program was originally considered, Congress recognized the potential difficulties of applying the standard SSA disability definition to children. Thus, under the original legislation, Congress wrote that a child should be considered disabled if "he suffers from any medically determinable physical or mental impairment of comparable severity" to a disabling impairment in an adult (SSA 1997). In practice, children originally qualified for SSI if they had "a medically determinable physical or mental impairment which results in marked and severe functional limitations, and which can be expected to result in death, or which has lasted or can be expected to last for a continuous period of not less than 12 months." Between 1974 and 1989 the child disability determination process did not include a functional assessment or take into account the equivalent of adult vocational factors. See Figure 3 for a comparison of the child and adult initial disability determination process.

This changed in 1990, when the Supreme Court decided the case of Sullivan vs. Zebley. The Court ruled that in order to meet the standard of equal treatment, a functional limitation component parallel to that of adults must be included in the initial disability determination process for children. In response, SSA added two new bases for finding children eligible for benefits: (1) functional equivalence, which was set at the medical listing level of the disability determination process; and (2) an individual functional assessment (IFA), which was designed to be parallel with the functional and vocational assessment provided for adults. By allowing applicants who did not meet the medical listing to be found disabled if their impairments were severe enough to limit their ability to engage in age-appropriate activities, such as attending school, the IFA lowered the level of severity required for children to be eligible for SSI benefits (GAO 1994, 1995).

In 1996, as part of welfare reform, Congress modified the definition of disability for children. Legislators replaced the comparable severity (to adults) criteria with a definition of disability that is 
unique to children. Under the new definition, a child's impairment—or combination of impairments — are considered disabling only if it (they) results in marked and severe functional limitations, is expected to result in death or has lasted or can be expected to last at least 12 months (SSA 1996)." The new focus on assessing the severity of impairments among children was reflected in changes in the evaluation process. The legislation removed the IFA, replacing it with a criterion based on functional equivalence or evaluations of the extent to which impairments create medical listing-level severity. The revised rules defined medical listing-level severity for functional limitations as: (1) marked limitations in two broad areas of functioning, such as social functioning or personal functioning; or (2) extreme limitations in one area of functioning, such as inability to walk (SSA 1997). In practice these changes meant that although functional limitations continued to include behavior-related limitations, they no longer covered the same breadth of functioning included in the IFA. For example, Congress specifically removed maladaptive behavior disorder from the functional listing criteria. Thus, the post-1996 standard represents a broader measure of disability than originally applied to children, but a narrower standard than the one used between 1990 and 1996 (see Figure 3).

Economic Resources Criteria. In addition to the categorical requirements-aged, blind, or disabled — applicants must also satisfy income and resource tests. To be eligible for SSI, an individual's countable income must be less than the federal benefit rate (FBR) — $\$ 500$ per month $(\$ 6,000$ per year) in 1999 — and countable resources must be less than $\$ 2,000 .{ }^{14}$ For couples, the amounts are 150 percent of the individual limits: countable monthly income of $\$ 751$ per month $(\$ 9,012$ per year) and $\$ 3,000$ in resources. Not all income received by individuals or couples is countable. Exclusions include a $\$ 20$ monthly income disregard for all forms of income with the exception of means-tested income and an

\footnotetext{
${ }^{14}$ The SGA and the means-test values for SSI eligibility may differ. The SGA limits are set occasionally, while the SSI FBR changes yearly with the CPI.
} 
additional $\$ 65$ monthly disregard for any labor income. ${ }^{15}$ After these disregards, for every $\$ 1$ in labor earnings a worker loses $\$ 0.50$ in SSI benefits. Therefore, after all income disregards, an SSI recipient faces a 50 percent implicit tax on labor earnings. ${ }^{16}$ In-kind assistance from government programs like Food Stamps and public housing are not counted as income against the individual's overall SSI benefit. All other benefits from government programs are taxed at 100 percent. Countable resources include resources other than the home a person lives in, a car (depending on use or value), and limited amounts of life insurance and burial funds. ${ }^{17}$ In cases where an eligible individual resides in a household with ineligible individuals, a portion of the other person's income is considered when determining the amount of the SSI payment. This process, known as "deeming," applies to married couples with one eligible member, parents of child applicants, and U.S. sponsors of noncitizen applicants. The deeming rules are straightforward; if an individual or couple is living in another person's household and is receiving both food and shelter from the person in the household, the federal benefit rate is reduced by one-third.

Although the federal benefit rate—and thus, the monthly income test—rise with inflation each year, the monthly income disregards, the asset limits, and the value of allowable assets (e.g., car, household effects) are not indexed, and thus have fallen substantially in real terms since SSI began. The real decline in the income disregards and asset limits over time effectively has eroded the value of SSI benefits and narrowed the population of potential recipients relative to 1974 levels. Consider first the disregards of \$20 on all income and \$65 on labor income set in 1972. Valued in 1999 dollars, these disregards would be $\$ 80$ and $\$ 259$, respectively. Adjusting the asset limits for inflation discloses the

\footnotetext{
${ }^{15}$ In certain cases, impairment-related expenses may be deducted from this total. Also, income is disregarded when it is used for Plans for Achieving Self Support (PASS).

${ }^{16}$ As we will discuss below, for those SSI beneficiaries receiving other means-tested program benefits the effective marginal tax on work can be much higher.

${ }^{17}$ In 1999 , the dollar value on disregards on assets include up to $\$ 4,500$ for a car or medical treatment, life insurance valued at less than $\$ 1,500$, and personal property and household furnishings valued at less than $\$ 2,000$.
} 
same pattern. Valued in 1999 dollars, asset limits would be $\$ 5,978$ for an individual, and $\$ 8,968$ for a couple, compared to the $\$ 2,000$ and $\$ 3,000$ limits currently in place. Thus, compared to when it began in 1972, SSI now covers a narrower and less economically advantaged portion of the income distribution.

Other Eligibility Criteria. In addition to meeting one of the three categorical requirements and the economic resource criteria, individuals also must meet residency and citizenship requirements. To be eligible for SSI an individual must be a resident of the United States and a U.S. citizen, a U.S. national, or a "qualified alien" in an SSI-eligible noncitizen category. ${ }^{18}$ The current SSI-eligible noncitizen categories generally can be characterized as covering individuals who were lawfully in the United States as of August 22, 1996, individuals who are refugees or in refugee-like situations, and individuals who have contributed to the country either by service in the military or through extended periods of work. Like the disability criteria for children, the relatively restrictive allowances for noncitizens were implemented under 1996 welfare reform (PRWORA), and were a direct response to concerns that newly arrived noncitizens with immigration sponsors were increasingly applying for, and receiving, SSI benefits. The SSI provisions in the 1996 welfare reform act generally excluded these individuals from receiving SSI by mandating that the income of the noncitizen's immigration sponsor be considered in the means test.

SSI Benefits

Federal Benefit Levels. In general, SSI beneficiaries with no countable income receive the maximum monthly federal benefit rate (FBR), \$500 in 1999 (\$751 for jointly eligible couples). The FBR is adjusted automatically each January by the cost-of-living index used to adjust all Social Security (OASDI) benefits. Although the original objective of the SSI program was to guarantee an income at the poverty level, from the beginning, the federal minimum SSI benefit was set below the official Bureau of

\footnotetext{
${ }^{18}$ The term qualified alien is defined in section 431 of P.L. 104-193, as amended by P.L. 104-208 and P.L. 105-33. See Parrot, Kennedy, and Scott (1998) for a complete listing of the qualifying criteria.
} 
the Census poverty line. Excluding state supplementation, SSI payments represent about 75 percent of the poverty threshold for an eligible individual, and about 90 percent of the threshold for an eligible couple; these percentages have remained relatively constant over time (U.S. House of Representatives 1998). ${ }^{19}$

SSI recipients are required by law to apply for every government program for which they may be eligible. In most states, recipients receive state supplemental payments and become eligible for Medicaid and Food Stamps without making a separate application. ${ }^{20,21}$ Since 1986 SSI benefits and eligibility for Medicaid have been continued for those who earn above the SGA; this is known as 1619(b) status. ${ }^{22}$ In general, the special eligibility test for Medicaid applies if the individual has earnings over the level that offsets their SSI benefits, but is still lower than a threshold amount established in the state in which they reside. ${ }^{23}$ Adult SSI recipients with disabilities also are eligible for federally-funded, state-administered vocational rehabilitation. ${ }^{24}$

${ }^{19}$ This difference arises in part because the SSI program and the U.S. poverty thresholds assume different economies of scale. The SSI program assumes that a single person needs 67 percent of the couple benefit to be equally well off; the U.S. poverty threshold assumes that a single person needs 80 percent of the couple benefit to maintain an equivalent standard of living.

${ }^{20}$ We discuss states' latitude in determining Medicaid eligibility for SSI recipients later in this section.

${ }^{21}$ In most cases, individuals who are eligible for SSI are categorically eligible for Food Stamps. The exceptions to this general rule are SSI beneficiaries living in households where other members do not receive and are not applying for SSI. These individuals must apply for Food Stamps at the local food stamp office and meet the household income test to obtain food stamp eligibility.

${ }^{22}$ In 1995 , only about 46,000 (1.3 percent) of the 3.5 million SSI disability recipients were in 1619(b) status (Mashaw and Reno 1996).

${ }^{23}$ In making this determination, the SSA takes the average expenditures on Medicaid and SSI (including state SSI) and compares this amount to an individual's earnings.

${ }^{24}$ The Ticket to Work/Work Incentives Improvement Act of 1999 expanded the eligible pool of vocational rehabilitation providers available to disabled SSI recipients, by allowing beneficiaries to receive vocational rehabilitation services from not-for-profit and for-profit vendors. 
State Supplementation. There are two types of state supplementation in SSI: mandatory and optional (see Table 4). ${ }^{25}$ Under mandatory supplementation, states whose Old-Age Assistance and Aid to the Permanently and Totally Disabled benefits were greater than the federal minimum had to make up the difference in mandatory state supplements. ${ }^{26}$ All but a few states were subject to mandatory supplementation requirements in 1972 (column 1, Table 4). ${ }^{27}$ States offering supplements can follow the same rules as the federal SSI program and have the program administered by SSA, or they can administer their own program and use a state-specific eligibility criteria. ${ }^{28}$ In 1999, 43 states and the District of Columbia provided optional supplemental benefits (column 2, Table 4).

Although a majority of states have optional supplementation programs, a number of factors minimize the importance of these programs. First, only 23 states provide supplements to the vast majority of SSI recipients living independently in their own households (column 3, Table 4). ${ }^{29}$ In the remaining states with optional programs, supplements are paid only to the minority of SSI recipients living in institutions (column 4, Table 4). ${ }^{30}$ Second, because state supplements are not annually adjusted

${ }^{25}$ For a detailed description of state supplementation see Ponce (1996).

${ }^{26}$ Mandatory state supplements applied to individuals receiving benefits in December 1973.

${ }^{27}$ Since mandatory supplementation applied only to individuals receiving benefits under pre-SSI programs, the prevalence of such payments has declined over time. In December 1996, approximately 2,800 recipients or less than 0.1 percent of all recipients were still receiving payments based on the mandatory supplementation rule (U.S. House of Representatives 1998).

${ }^{28}$ Despite the apparent cost-advantage to federal administration, states have increasingly opted for state administration of supplemental payments. Since 1974, seven states have shifted from federal to state administration (U.S. House of Representatives 1998). In 1999, 15 states and the District of Columbia currently contract with SSA to administer their SSI supplementation programs

${ }^{29}$ Over 90 percent of SSI recipients live in their own households (U.S. House of Representatives 1998).

${ }^{30}$ One explanation for the ongoing supplementation of SSI recipients living in institutions is that supplementary SSI payments provide states with a mechanism of supporting such facilities. 
for inflation, the real value of the median state supplemental payment to individuals living independently declined by about 60 percent between 1975 and $1997 .{ }^{31}$

In addition to supplementing federal SSI payments, states also have latitude in determining Medicaid eligibility for SSI recipients (see columns 5-7, Table 4). States may elect among three options:

(1) have SSA automatically grant SSI recipients Medicaid eligibility without separate application; (2) provide Medicaid eligibility for all SSI recipients, but only if the recipient completes a separate application with the state agency that administers the Medicaid program; or (3) impose Medicaid eligibility criteria more restrictive than the federal SSI criteria, known as the "209(b) option." ${ }^{32}$

\section{Administration and Financing}

As a federal income maintenance program, SSI is funded from general revenues and is administered by the Social Security Administration. Although, as discussed earlier, many states supplement federal benefit levels, over time the share of supplemental benefits paid by states has declined. In 1975, state SSI expenditures accounted for approximately 27 percent of total SSI payments. In 1998, state supplemental payments amounted to about 13 percent of annual SSI expenditures (SSA 1999). ${ }^{33}$ Because the Federal government pays for the bulk of SSI benefits (100 percent in some states), while states pay for Temporary Assistance to Needy Families (previously AFDC) states have an incentive to move individuals from state-financed welfare programs to federally funded SSI. This fiscally-based incentive may, in part, explain the active role state welfare agencies play in SSI outreach programs.

${ }^{31}$ Over time some states have even reduced the nominal value of supplemental payments.

${ }^{32}$ The criteria applied cannot be more restrictive than the state's approved Medicaid state plan in January 1972 .

${ }^{33}$ The numbers reported reflect the average for all states. Looking across states, in January 1999, the federal share of the maximum SSI benefit ranged from 58 percent in Alaska and 74 percent in California to 100 percent in the eight jurisdictions without a supplemental program (CRS 1999). 


\section{Program Statistics}

Trends in Expenditures, Caseloads, and Benefits

The SSI program has grown substantially in both recipients and expenditures since it first paid benefits in 1974. However, its growth has varied over time (Figure 4). Between 1974 and 1982, caseloads fell by 4.5 percent and real federal expenditures declined by about 15 percent. This decline caused concern among policymakers that too few potentially eligible recipients were enrolling (Menefee, Edwards, and Schieber 1981). After this slow start, the number of SSI beneficiaries increased steadily until 1996, growing from roughly 3.9 million in 1982 to 6.6 million in 1996, a 70 percent increase. Federal payments for the program rose even faster during this period with the greatest growth between 1989 and 1992. Valued in 1998 dollars, total annual payments increased from $\$ 15.3$ billion in 1982 to \$29.9 billion in 1996, an increase of about 95 percent. Between 1996 and 1998 (the last year of data available) caseloads have fallen slightly and expenditures have risen by less than 2 percent. Despite growth in SSI over time, SSI expenditures as a percentage of total federal outlays have remained relatively stable at 1.9 percent since the program began in 1974 .

\section{Trends in Characteristics of Recipients}

Originally considered a program for the elderly, SSI is now dominated by adults and children with disabilities. Figure 5 shows the age composition of SSI beneficiaries between 1974 and 1998. In 1974 , the majority of the SSI caseload was over the age of 65 . The number of aged beneficiaries peaked at 2.5 million in 1975, gradually dropped to around 2 million in 1982, and remained at about that level to 1998. In contrast, the number of blind and disabled adults (aged 18-64) on SSI has more than doubled since 1974, with the most rapid growth occurring after 1982. ${ }^{34}$ In December 1998, 3.6 million adults received SSI benefits, nearly 2 million more than in 1982. The number of blind and disabled recipients

\footnotetext{
${ }^{34}$ This growth is almost entirely due to increases in the number of disabled beneficiaries. The number of working-age SSI recipients eligible due to blindness has remained relatively constant over time (Annual Statistical Supplement, SSA, various years).
} 
who are under age 18 also has grown rapidly in recent years. ${ }^{35}$ Between 1974 and 1989 the child caseload increased to about 185,000. Following the Zebley decision in 1990, the number of blind and disabled children rose rapidly, reaching 955,000 by 1996 . Since then, child SSI rolls have declined slightly, falling to 887,000 in 1998 . Hence, although blind and disabled adults and children comprised only 40 percent of the SSI population in 1974, their share in the SSI population had grown to 70 percent by 1998 .

As the basis for eligibility and the age composition of SSI recipients have changed, so have a number of other key demographic characteristics. Table 5 reports on trends in a number of recipient characteristics from 1974 to 1996 . The first section of the table shows the gender, racial, and citizenship composition of all SSI recipients. Since 1975, the proportion of males and non-whites has increased. In 1976, more than two-thirds of SSI recipients were female and about 64 percent were white. In 1996, about 60 percent of SSI recipients were female and the proportion of white recipients had fallen to 52 percent. Another notable change in the composition of the SSI population has been the rapid increase in the number of noncitizens receiving benefits. In 1982, the first year for which records on citizenship were kept, a little over 3 percent of all SSI recipients were noncitizens. In 1994, two years before citizenship became a requirement for new applicants, about 12 percent of all SSI beneficiaries were noncitizens. This percentage fell slightly once the citizenship restrictions were imposed, but noncitizen beneficiaries remained a sizeable component of the SSI population-11 percent in 1996.

The second section of Table 5 shows trends in the three main qualifying diagnostic categories - physical impairments, mental retardation, and mental impairments other than mental retardation-for SSI recipients with disabilities (adults and children) In the early years of the program, less than one-quarter of SSI beneficiaries qualified on the basis of mental impairments other than mental retardation. Following expansions in the eligibility criteria for mental impairments in both adults and

\footnotetext{
${ }^{35}$ Again the growth is almost entirely explained by increases in the number of disabled children.
} $-18-$ 
children, the number of adults and children qualifying for SSI on the basis of a mental impairment began to grow. As a result, in 1998, more than 30 percent of all SSI recipients qualified on the basis of mental impairments other than mental retardation.

\section{SSI Participation}

An important policy concern with respect to all public assistance programs is the degree of participation among eligible individuals. That is, of the people who meet the categorical, economic resource, and citizenship tests, what proportion are receiving SSI benefits. It is relatively straightforward to make such calculations for those aged 65 and older and a literature exists on this question.

Unfortunately, the difficulties of establishing and assessing disability for adults and children not only makes if difficult for policymakers and administrators to accurately determine SSI eligibility for those who apply, but also for researchers to calculate program participation rates that require some estimate of the eligible disabled population that does not apply for benefits. Existing nationally representative data sources either lack sufficient information on economic characteristics or health characteristics to generate precise estimates of the population eligible for the disability components of SSI. As a result, there is almost no research on SSI participation rates among the eligible population with disabilities. ${ }^{36}$

In Table 6 we provide a preliminary approximation of "take-up rates" for SSI that we believe is useful in establishing broad trends. We use the official U.S. Bureau of the Census poverty calculations and show the share of SSI recipients in age-based poverty populations. This method was used in the 1998 Green Book for the population aged 65 and older. On the one hand, because our estimates do not account for citizenship, assets, and most especially disability status, they will understate program participation among those in the poverty population who are eligible. On the other hand, since those eligible for SSI may have household incomes above the official poverty line, our approximations may

\footnotetext{
${ }^{36}$ It is possible to estimate the population with some level of disability using national data sources (see Bound and Burkhauser 1999 for examples). It is much more difficult to isolate the sub-population within this broader category that would meet the medical listing or vocational criteria for SSI eligibility.
} 
overstate program participation among all eligible households. Nonetheless, the trends in Table 6 are revealing of how SSI is being used by low income persons.

As the first column of Table 6 shows, the participation rate among the poor elderly declined from around 79 percent in 1974 to about 54 percent in 1982. Since then, participation rates have fluctuated from year to year, but have remained well below the highs recorded in the early years of the program. In general, no more than two-thirds of elderly individuals living in poverty receive SSI benefits. More complete measures of participation suggest that take-up rates among the elderly are lower than the gross measures indicate. Researchers consistently find the participation rate among persons eligible for SSI aged benefits at between 45 and 60 percent (Menefee, Edwards, and Schieber 1981; Warlick 1982; Coe 1985; Shields et al. 1990; McGarry 1996).

The remaining columns in Table 6 show SSI participation rates for poor adults age 18-64 and poor children. Consistent with the caseload growth highlighted in Figure 5, participation rates among poor working age adults and children have risen over time. Participation rates among poor adults rose from about 15 percent in 1974 to more than 20 percent in 1998, with the most rapid increases occurring during the 1990s. Recipiency rates for poor children also increased rapidly during the 1990s, rising from 2 percent in 1989 to 6.6 percent in 1998. As column four shows, the prevalence of disability has not risen since 1980 which suggests that the increase in SSI take-up rates among the poor is not a function of increased disability.

\section{Multiple Program Participation among SSI Beneficiaries}

A large fraction of SSI beneficiaries participate in other government programs. Table 7 shows that in 1995, almost 40 percent of all SSI recipients also received Old Age, Survivors, and Disability Insurance (OASDI), either for retirement or disability. All SSI recipients were eligible for Medicaid and about 30 percent were eligible for Medicare. One-half lived in households receiving Food Stamps and three in ten lived in a household receiving Women, Infants, and Children (WIC) or reduced price meals. 
Finally, about one-quarter of SSI recipients lived in public or subsidized housing. Over time, the percentage of SSI recipients receiving Social Security and Medicare has been declining, while the percentage of recipients receiving Food Stamps, WIC, free or subsidized meals, and public housing has been rising (U.S. House of Representatives 1998.)

The fact that a growing share of SSI recipients receive benefits from multiple means-tested programs suggests that the work incentives faced by the typical beneficiary are increasingly complex. SSI beneficiaries face multiple implicit taxes in the form of reduced benefits from SSI and any other transfer programs, plus the regular assortment of federal, state, and local taxes, as well as the loss of medical insurance for those not meeting the 1619(b) provisions. As others have shown, the cumulative marginal tax rates for individuals receiving multiple programs can be quite high (Giannarelli and Steurle 1994; Keane and Moffitt 1998).

Although the empirical literature on the effects of changes in these various marginal tax rates will be discussed later in this chapter, it is useful to lay out the tax circumstances SSI recipients potentially face. Figure 6 (from Burkhauser and Wittenburg 1996) shows how a single male's 1994 net income changes with each additional dollar of his labor if he is eligible to receive the federal SSI benefit of $\$ 458$ and the average cash value of Medicaid insurance for SSI disability of $\$ 540$ per month. With no labor earnings, this person would receive \$998 per month in SSI benefits and Medicaid insurance.

As the figure shows, the interaction of the Earned Income Tax Credit (EITC) and federal taxes as well as Food Stamps, which one-half of all SSI beneficiaries receive, significantly alters the marginal tax rates faced by recipients with various amounts of labor earnings. The EITC phase-in subsidy to work offsets social security (FICA) taxes, but because the food stamp program subtracts 24 cents in Food Stamps for every dollar of labor earnings, the net tax on the first dollar of labor earnings is 23.85 percent. This tax rate continues to the SSI disregard level of $\$ 85$ per month. At this point the 50 cent loss in SSI benefits per dollar of labor earnings interacts with the food stamp program taxes on work, resulting in a 
net tax of 58.85 percent. When the EITC plateau begins, the net tax on labor earnings rises to 66.5 percent and when the EITC phase-out tax begins, the net tax on labor earnings rises to 74.15 percent. When the federal income tax standard deduction level is passed and federal income tax starts, the marginal tax rate rises to 89.15 percent. Marginal tax rates only begin to fall after Food Stamps and EITC break-even points are reached. The final increase in tax rates occurs just before SSI benefits phase out, when all Medicaid benefits are lost because earned income now equals the Medicaid special eligibility plateau. The reduction of such cumulatively high marginal tax rates via a single universal income support program was one of the arguments made in support of President Nixon's original FAP program.

\section{Review of Economic Issues}

Although economic analysis of social programs frequently takes the goals of the program as given, with SSI the motivation for the program is itself an important determinant of how we view the behavioral reactions to it. In this section we first discuss the economic rationale behind a federal income floor for the subset of the poor who are aged, blind, or disabled. Next, we review the theory related to individual responses to the existence and structure of SSI including takeup, work, savings, and disabilityreporting behavior. Finally, we consider the equity goals of SSI and discuss attempts to evaluate program effectiveness.

\section{Public Income Provision for the Aged, Blind, and Disabled}

As noted earlier, SSI was born out of a failed effort to provide a guaranteed income floor under all Americans-FAP. Hence, while the motivation for providing an income floor to the subset of the adult poor who are aged, blind, or disabled is primarily distributional, it also rests on a political compromise that offered this entitlement only to categories of individuals not expected to work. While this compromise allowed SSI to pass in 1972, social expectations regarding work have changed over time for the three groups targeted by SSI — the aged, blind, and disabled. Individuals are living and working 
longer; the normal retirement age for Social Security benefits has been raised; and the Americans with Disabilities Act (ADA) has granted people with disabilities a legal right to equal access to employment.

Although work expectations have risen for the aged, it is people with disabilities who have experienced the largest shift in public attitudes. In 1990, people with disabilities successfully argued that unequal access to jobs—rather than an impairment—is the primary barrier to employment opportunities. As a result, people with disabilities gained legal rights to accommodation under Title I of the ADA. Some disability advocates even have argued that there is no such thing as a disabled worker; rather, there is only a society that does not provide the appropriate accommodations for such individuals. In a world of full accommodation, the disability-transfer population should be zero. Such attitudinal changes raise basic questions about how society should treat people with disabilities. Most fundamental of these questions being, should people with disabilities categorically be expected to work or not?

These types of cultural changes potentially shift the boundaries of the population not expected to work and hence eligible for a categorical guaranteed income floor based on age or disability. As the opportunities for employment and the demand for the productivity of people with disabilities and those over age 65 increase, the clear categorical lines drawn between them and other groups with similar difficulties finding work, such as low-skilled or less-educated younger persons, or single mothers facing welfare limits, are increasingly blurred.

The original political compromise that made the families of disabled children eligible for SSI was slightly different, and represented a departure from the not expected to work criteria applied to the aged and to adults with disabilities. Some argued that SSI benefits for disabled children replaced the earnings of parents forced to reduce their work effort in order to care for their newly disabled child. Others argued that SSI-children benefits indirectly offset extra disability-related household expenses. In both cases, SSI-children benefits were intended to offset lost income and partially return the family to its previous level of economic well-being. (See NASI 1995 for a fuller discussion of these issues.) 


\section{SSI and Behavioral Change}

If the aged and disabled adults are neither able or expected to work, then many of the disincentives discussed in regard to other means-tested transfer programs are irrelevant. In such a world, cumulative marginal tax rates could approach 100 percent with no change in work behavior and SSI could provide relatively high income guarantees and still maintain relatively low break-even points (the income level at which a person is no longer eligible for benefits). Moreover, to the degree that age and work disability are clearly defined and immutable categories, differences in the guarantees, time-limits, or funding mechanisms for SSI and other programs would have little effect on SSI allowances and caseloads. In such a world SSI program participation is purely a function of the prevalence of health limitations in the low income population. Below we suggest that none of these premises hold with respect to the disability component of SSI. Thus, SSI policymakers must take behavioral changes on the part of potential SSI recipients and state and local governments into account when establishing program eligibility criteria and considering future program rules.

Propensity to Apply for SSI. Disability is neither a static or precise concept. Responses to the onset of health conditions depend not only on the severity of the impairment, but also on the social environment that people with health impairments face-including the availability of employment, the availability of accommodation, rehabilitation and retraining, the presence of legal supports or protections, and the accessibility and generosity of SSI and other government transfer programs. The propensity for individuals to apply for SSI benefits depends on the probability the place on their health impairment and vocational circumstances being sufficient to meet the SSI disability eligibility standards as well as on their employment potential and the generosity of SSI relative to other forms of public assistance. The latter comparison is particularly relevant in light of 1996 welfare reform (PRWORA) that restricts the access to, and generosity of, alternative public assistance programs. If low-income 
adults have health conditions or have children with health conditions, the relative generosity of SSI to other alternatives may induce individuals to apply for benefits.

Program Participation and Work Incentives. The economics of program participation and labor supply for individuals potentially eligible for SSI mirrors the analyses of these issues in programs such as AFDC and TANF. Thus, to understand the work disincentives embodied in the SSI program, we turn to the framework used for other categorical welfare programs. Moffitt (1983) provides a discussion of the basic economic issues. In these models individuals make choices that depend on the income gained from the program and the costs of participating, including the time and money costs associated with applying for and maintaining eligibility for benefits.

To see how this works in the case of SSI, consider the conventional labor-leisure model diagramed in Figure $7 .{ }^{37}$ Figure 7 compares the budget constraint of an SSI program with a 50 percent marginal tax rate, $(t=0.5)$ and one with a marginal tax rate of 100 percent $(t=1.0)$. Segment ACDE of the figure represents the budget constraint of those not categorically eligible for SSI. The line has a slope equal to the hourly wage rate, $w$. Segment ABCDE applies to those same individuals if they are categorically eligible and they face a marginal tax rate of 100 percent. Benefits are taxed one dollar for each dollar earned and phased out at the break-even level (point C). That is, even though they are categorically eligible for benefits, their labor earnings offset all SSI benefits at hours levels greater than point C. Segment ABDE applies to those same people but now they face a marginal tax rate of 50 percent. Benefits are taxed at a rate of 50 cents per dollar earned and the break-even hours point is D. Under this model, categorical eligibility for SSI benefits unambiguously reduces work effort relative to not being categorically eligible. There is an income effect associated with the guarantee (AB), and a substitution effect associated with the marginal tax rate (BC or BD). The income and substitution effects

\footnotetext{
${ }^{37}$ This discussion draws from the expositions in Moffitt (1986), Hoynes and Moffitt (1995), and Moffitt's review of the AFDC/TANF program in this volume. This discussion is made primarily in the context of adults with disabilities.
} 
work in the same direction, and hours of work among participants fall. Only those whose optimal hours worked prior to program eligibility were beyond the break-even hours point may not be affected and even then it will depend on the shape of their indifference curve (i.e., some would be willing to accept less income by substantially reducing work and living on program benefits).

The next question to ask is what happens if the marginal tax rate is reduced. Here the answer is unclear; the net effect of a reduction in $t$, from 100 percent (BC) to 50 percent (BD), is ambiguous. The arrows in the Figure 7 show the various responses that could occur following a reduction in the marginal tax rate (represented by a shift from segment $\mathrm{BC}$ to $\mathrm{BD}$ ). For individuals initially receiving SSI benefits and not working (i.e., initially at point B), a reduction in the tax rate may encourage participants to work more, represented by Arrow 1. At the same time, a reduction in $t$ expands the range of individuals eligible for benefits, and brings some portion of those categorically eligible but not previously receiving SSI onto the rolls. As these individuals move onto SSI their work effort is reduced, as shown by Arrow 2. Arrow 3 shows that some categorically eligible individuals who continue to earn too much under the lower tax rate may be motivated to reduce their hours of work enough to become eligible for benefits, thereby combining work and SSI benefits. Finally, it also is possible that a reduction in $t$ will increase payments by enough to induce previously eligible persons on earnings grounds but not on categorical grounds (segment AC) to risk entry onto the rolls.

Taking each of these possibilities into account, the net effect of a lower marginal tax rate on work effort is ambiguous. The only thing that is clear is that lower marginal tax rates increase caseloads. A lower tax rate makes more categorically eligible individuals eligible for the program on income grounds and, given positive takeup rates, unambiguously boosts the number of individuals on the rolls. Moreover, by lowering the costs associated with staying on the rolls, lower marginal tax rates reduce exit rates from the program, thereby increasing caseloads. Finally, lower marginal tax rates may induce those 
on the margin of categorical eligibility on health grounds to apply for benefits since the gains to program acceptance have increased.

Unlike SSI benefits for the elderly, where categorical age eligibility is easily demonstrated and benefit receipt is automatic if one meets the means test, categorical eligibility for SSI benefits is more difficult to demonstrate. Thus, eligibility for benefits is not certain and models of SSI application must take this risk of non-acceptance into consideration. In general, those considering applying for SSI will value disability benefits with a probability of less than one. Holding the underlying health condition constant, the probability of acceptance onto the rolls will depend on the disability screening process. Conditional on the same impairment, tighter eligibility criteria are likely to increase the probability of denial and reduce the expected value of applying. In contrast, looser criteria increase the probability of acceptance and increase the expected value of applying. ${ }^{38}$ In either case, individuals facing uncertainty surrounding acceptance, informational hurdles, or stigma associated with benefit receipt, may be induced to participate by the increase in benefits associated with the lower marginal tax rate.

If those categorically eligible for benefits on health grounds are completely unable to perform any substantial gainful activity under any circumstances then there is no need to lower the marginal tax rate on SSI, since those on the program are neither expected or able to work. However, to the extent that work is both possible and expected for people with disabilities who meet the other eligibility criteria, policy discussions with respect to trade-offs between tax rates, guarantees, and break-even points become much closer to those taking place for other income maintenance programs.

The same model also incorporates stigma and other fixed program costs. As in other income maintenance programs, the presence of stigma and other program costs associated with applying for

\footnotetext{
${ }^{38}$ Weathers (1999) develops a multi-period model of the SSDI application process in which the optimal time of application following the onset of a disability is a function of the opportunity cost of lost wages versus the gain in SSDI, adjusted for the probability of acceptance. A similar model could be used to predict the timing of SSI-disability applications.
} 
benefits explains why some categorically eligible individuals are observed on segment ACD. As fixed program costs and stigma decline, participation among this group will rise. What the model in Figure 7 does not show are potential program interaction effects. As discussed in Figure 6, the actual budget constraint facing those categorically eligible for SSI benefits is more complex, with more nonlinearities due to the cumulation of taxes from multiple programs. In like manner, multiple program eligibility will cause complications for those interested in the behavioral effects of other transfer programs. Burkhauser and Smeeding (1981) show the incentives to accept actuarially reduced Social Security benefits (OASI) at younger retirement ages are increased for those who would be eligible for both SSI and OASI at age 65, since OASI benefits are taxed on a dollar for dollar basis by SSI.

Finally, one can also use the model in Figure 7 to think about the labor-supply behavior of parents of children with disabilities. If a child is judged eligible for SSI benefits, then an able-bodied parent faces the same marginal tax rates, guarantees, and break-even points shown in Figure 7. Stigma, information costs, and reduced program benefits (adjusted for the probability of acceptance) also apply. One additional issue that affects parents of children with disabilities is how benefit receipt will influence the future well-being of the child.

Savings Behavior. The presence of asset testing in the eligibility criteria for SSI may reduce saving among those meeting other eligibility criteria. This point is made generally about means-tested programs. Hubbard, Skinner, and Zeldes (1995) argue that when eligibility is tied to assets, individuals meeting the income test have incentives to reduce their savings in order to qualify for benefits. Among those applying for SSI benefits, the most likely group to be affected by the asset test is the elderly, who may have accumulated savings over their lifetime.

\section{Balancing Efficiency and Equity Concerns}

Our discussion above has focused on the behavioral effects of the SSI program. This focus on the efficiency costs of SSI induced behavioral change ignores the social benefits of SSI and may may 
lead some to conclude that a socially optimal SSI program would have no behavioral impact on benefit applications, work, or savings. This conclusion is inappropriate for two reasons. First, even if actual disability status were perfectly observable, society would probably still want to target some level of benefits on disadvantaged low income workers and their families even if it resulted in some efficiency losses. Hence the more important question is not whether there are program related behavioral changes but whether they are small relative to the social gains from redistributing income to less advantaged persons. Analyses of the welfare implications of the SSI program should focus on this second and more important question.

Second, in a world where the socially appropriate eligibility standard for SSI is difficult to assess, some individuals will be denied benefits who are less capable of work than is socially acceptable. In such a world, a more lenient eligibility criteria will involve a trade-off between the reduction of type II errors on the one hand and the additional costs of type I errors on the other. The issue is: in the presence of uncertainty, do the social benefits outweigh the efficiency costs arising from increasing the probability of guaranteeing an income floor to those below some minimum level of work capacity at the cost of also providing these funds to some who are more capable of work. In both cases, it is appropriate to assign some value to SSI as a mechanism for providing social protection against the economic consequences of aging and disability for disadvantaged workers. To do otherwise would be to hold too narrow a view from a social policy perspective. See Bound, Cullen, and Schmidt 2000 for a fuller discussion of these issues.

\section{Review of the Evidence}

In the previous section we reviewed the potential consequences on application, work, and savings behavior of SSI program rules and showed that if the aged or disabled adults are capable of work, the SSI program rules could their influence behavior. We also discussed how SSI program rules could affect the work behavior of the parents of children with disabilities. In this section we review the empirical 
literature on the effects of the existence and structure of SSI on behavior. Despite the size and importance of the SSI program, the empirical literature on its behavioral effects is relatively small.

Moreover, almost without exception, empirical studies focus on only one of the three groups SSI targets. For this reason, the empirical evidence on the behavioral effects of SSI for each target population group will be discussed in turn.

SSI and Adults with Disabilities

Work Effort of Adults with Disabilities. ${ }^{39}$ To understand the relative importance of SSI to the population with disabilities, it is useful to focus on how successfully people of working-age with disabilities are integrated into the labor force. Table 8 uses data from the 1989 Panel Study of Income Dynamics (PSID) response-nonresponse file (columns 1-4) and the 1990 Longitudinal Survey of Income and Program Participation Microdata (SIPP) file (columns 5-8) to measure labor force participation and transfer receipt of people with disabilities prior to the passage of the ADA. Although work is less common among the working-age population with disabilities than among those without disabilities, it still is an extremely important activity. Among working-age men with disabilities in 1988, two of every three men worked in the labor market and 43 percent worked full-time.

The importance of work in the population of disabled adults is confirmed by the SIPP data. ${ }^{40}$ Although the percent working (54.8 percent) is lower in the SIPP than in the PSID, as is the percent either working full-time or self-employed (41.1 percent), work is still highly prevalent among men with disabilities. Part of the reason for the difference in work reported in these two data sets is related to the different years in the business cycle captured in the data. The year 1988 was near the peak of the 1980s

\footnotetext{
${ }^{39}$ This discussion draws from Bound and Burkhauser (1999).
}

${ }^{40}$ The SIPP values in Table 8 come from Wittenburg (1997), who used a definition of disability similar to that of Burkhauser and Daly (1996). Because of the staggered nature of the SIPP panel, the wave 3 and wave 6 data used will capture a calendar year for respondents somewhere between October 1990 and January 1992. 
business cycle and represented the sixth straight year of economic growth. In contrast, the SIPP data center around 1991, the trough year of the 1990s business cycle. As a number of authors have shown, the employment of people with disabilities is sensitive to the business cycle (Burkhauser, Havemen, and Wolfe 1990; Daly 1994; Burkhauser, Daly, and Houtenville 2000).

Table 8 does not suggest that pathologies cannot result in serious employment limitations, or that health never prevents work. Even using the PSID data, approximately one-third of working-age men and almost one-half of working-age women with a disability had no labor earnings in 1988. Among this nonworking subgroup of the population with disabilities, nearly 70 percent of men and 43 percent of women received a disability transfer payment in that year. In the recession period captured in the SIPP data, the percent of the male population with disabilities not working is even larger -45.2 percent—and nearly three men in four in this nonworking population receive some form of government transfer. However, the fact that a significant fraction of the population with disabilities works raises questions about the justification for providing benefits to disabled SSI recipients based on an expectation of no work.

Factors Affecting SSI Participation. While application for SSI disability benefits is a function of health, it also is influenced by program rules and benefits. These include eligibility criteria and the generosity of benefits relative to work, the comparative generosity and availability of other means-tested welfare and social insurance programs, macro economic conditions (national, state, and local), and applicants' education and job skills. During the 1990s, considerable attention was devoted to understanding the link between these non-health factors and SSI caseload growth. The following discussion reviews the evidence on determinants of SSI caseload growth, looking first at the relationship between caseload dynamics and screening stringency (benefit supply), and then at factors affecting the demand for SSI benefits, including ease of benefit access, benefit generosity relative to work and other programs, and economic conditions. 
SSA began modifying its disability determination process in the mid-1970s. Concerned that state offices were not consistently and uniformly applying the residual functional capacity (RFC) and vocational standards in adult disability determinations, in 1979 SSA published regulations specifying who was to be classified as disabled, essentially tightening the eligibility criteria. SSA also tightened its policy towards benefit terminations in continuing disability reviews (CDRs) by state Disability Determination Services (DDS), permitting benefit termination without proof of medical improvement. This policy resulted in a three-fold increase in the number of cessation decisions on continuing reviews by state agencies (The Lewin Group 1999). Consistent with the tighter standards, the yearly allowance rate (initial acceptances divided by initial applications) of adult SSI disability applications began to fall in 1976 (Table 9).

The Social Security Disability Amendments of 1980 continued the trend of tightening the disability determination and review process. Importantly, the 1980 law changed both the frequency and nature of medical eligibility reviews done on disability beneficiaries. ${ }^{41}$ Before 1980 , the only beneficiaries targeted for medical eligibility review were those who had conditions that were likely to improve over time. The new law stipulated that all beneficiaries periodically should receive continuing disability reviews, and that all but those deemed to have permanent disabilities should be reviewed every

\footnotetext{
${ }^{41}$ The 1980 law tightened Social Security Administration control over the state disability determination services. In particular, SSA previously had reserved the right to review initial determinations before they were transmitted to the applicant, but during the 1970s it reviewed only 5 percent. The 1980 amendments required that SSA review two-thirds of successful applications. To enforce administrative control over administrative law judges, the secretary of Health and Human Services was empowered to appeal administrative law judge rulings that were favorable to the applicant.

Prior to 1980, the law provided that disability determinations be performed by state agencies under an agreement negotiated by the states and the Secretary of Health and Human Services. The 1980 amendments required that disability determinations be made by state agencies according to regulations of the Secretary. It also required the Secretary to issue regulations specifying performance standards to be followed in the disability determinations, and if the Secretary found that a state agency was failing to make disability determinations consistent with regulations, then the Secretary was required to terminate the state's authority and assume federal responsibility for the determinations.
} 
three years. The 1980 law made permanent the practice of using the same standards in CDRs that were applied when initially evaluating claimants. In addition to tightening the disability adjudication and review process, the 1980 law established two key work incentives: (1) the 1619(b) provision; and (2) the deduction of impairment-related work expenses (IRWEs) from earnings when determining the SGA. As noted earlier, the 1619(b) provision authorized a three-year demonstration project, allowing for the payment of special SSI benefits (and the retention of Medicaid coverage) for SSI recipients who exceeded the SGA level. Section 1619 became permanent in 1986.

As could be expected, the 1980 law had a discernible impact on administrative practice. As demonstrated in Table 9, the yearly allowance rate for adult SSI disability recipients fell from a high of 52.6 percent in 1975 to 26.6 percent in 1982 . The number of recipients fell from 1.75 million in 1978 to 1.66 million in 1982. This decrease occurred despite the economic recession of 1980-1982. This removal of individuals from the rolls generated a major political response. Most of the people removed from the rolls appealed the decision, requesting a hearing before an administrative law judge and causing a huge backlog of cases. As a result, some state governors instructed their DDS service not to terminate anyone from the disability rolls unless that person's conditions had improved. ${ }^{42}$

In 1984, in response to concerns that federal disability policy had become too restrictive, the Social Security Administration agreed to a moratorium on CDRs pending the enactment and implementation of revised guidelines. The 1984 law had profound effects on the standards used to evaluate a person's potential eligibility for SSI. When reviewing existing beneficiaries, the burden of proof was shifted back to the SSA to show that a beneficiary's health had improved sufficiently to allow him or her to return to work. A moratorium was imposed on re-evaluations of the most troublesome cases - those that involved mental impairments or pain—until more appropriate guidelines could be developed. Finally, benefits were continued pending the outcome of an appeal.

\footnotetext{
${ }^{42}$ For a fuller discussion of disability policy in this period, see Berkowitz and Burkhauser (1996).
} 
The 1984 law substantially increased the weight given to source evidence (i.e., evidence provided by the claimant's own physician) by requiring that it be considered first, prior to the results of an SSA consultative examination. SSA also was required to consider the combined effect of all impairments, whether or not any one impairment was severe enough to qualify a person for benefits. Perhaps most important, the SSA substantially revised its treatment of mental illness, reducing the weight given to diagnostic or medical factors, and emphasizing the ability of an individual to function in work or work-like settings.

Table 9 shows that the dip in the SSI adult disability population which occurred between 1978 and 1982 was reversed thereafter, and rose about 4 or 5 percent a year during the economic growth years of the later 1980s. When the next economic downturn came in the early 1990s, conditions were ripe for a surge in applications and in the number of people on the SSI disability rolls. The increases in the disability transfer population in the early 1990s exceeded anything seen in SSI since the start of the program. The annual acceptance rate for SSI adult disability benefits was almost 45 percent in 1992, the highest since 1976. Economic recovery and Congressional action with respect to SSI disability eligibility have slowed the growth in the working-age adult SSI population, but acceptance rates remain well above those in the 1980s, suggesting that a future downturn in the economy could result in an increase in the rolls. $^{43}$

The legislative history underlying the disability screening process highlights how the supply of benefits has changed over time. Figure 8 shows that demand for SSI disability benefits also has fluctuated. Fluctuations in applications have been as large as changes in the SSI disability rolls. To

\footnotetext{
${ }^{43}$ As part of more general welfare reforms in 1996, Congress removed drug and alcohol addiction as allowable conditions for SSI eligibility. In 1995, there were about 135,000 SSI recipients whose disability was based solely on drug addiction or alcoholism. The Congressional Budget Office estimated that about 65 percent of these individuals would be eligible for SSI based on other sufficiently disabling conditions. For a full discussion of these reforms and their impact see U.S. House of Representatives (1998).
} 
some extent these fluctuations have mirrored changes in eligibility standards, contracting when eligibility standards were tightened in the late 1970s and early 1980s, rising after the relaxation of eligibility standards in 1984, and falling again following the tightening of standards in the mid-1990s. However, other factors including local economic conditions, outreach efforts by both SSA and state governments to search for eligible candidates, and the generosity of SSI relative to other programs all are likely to have contributed to the variability in applications over time.

A number of scholars have estimated the link between local economic conditions and SSI application rates. The fact that SSI is a national program restricts the extent to which regional variation in benefits can be used to identify the effect of the program on applications. However, in recent work Black, Daniel, and Sanders (1998) used regional variation in economic conditions to identify the effect of financial incentives on the decision to apply for SSI (and SSDI) disability benefits. In particular, they examined the impact of the coal boom during the 1970s, and the coal bust during the 1980s on the number of SSI beneficiaries. Using panel data on 186 counties in Kentucky, Ohio, Pennsylvania, and West Virginia they estimated an elasticity of program payments with respect to local area earnings of between -0.5 and -0.7 for SSI recipients. While these results lend some support to the notion that labor market conditions in an area affect the decision of individuals to apply for disability benefits, the point estimates are hard to interpret. Black, Daniel, and Sanders interpret the estimated coefficient on the local earnings variable as reflecting the effect of changes in the financial attractiveness of disability benefits. However, given the nature of the specification used, it is possible that the earnings variable is picking up the effect of general economic conditions rather than the relative financial attractiveness of SSI. ${ }^{44}$ Furthermore, their estimates reflect the short-run effect of changes in the local economies in Kentucky, Ohio, Pennsylvania, and West Virginia on the number of disability beneficiaries. Given the fact that the

\footnotetext{
${ }^{44}$ As will be discussed shortly, the evidence that recessions lead to increases in the number of applications for SSI is strong.
} 
typical SSI spell is lengthy in duration, long-run effects likely will be substantially larger than short-run effects.

A considerable amount of government-sponsored research has attempted to explain the dramatic growth in the SSI population in the early 1990s. A useful summary of this work can be found in Rupp and Stapleton (1995). Much of this analysis has used the considerable variation in state-level applications and awards to test their models. Using cross-state data from 1988-1992 Stapleton, Coleman, and Dietrich (1995) find convincing evidence that the recession of the early 1990s contributed to the rapid rise in the number of applications for SSI benefits. They estimate that a 1 percentage point rise in the unemployment rate was associated with a 2 percent rise in applications for SSI. The effects on final awards were somewhat lower. Finally, they found that the changes in the unemployment rate had a smaller effect on benefit awards than on applications, suggesting that recessions induce those with less severe disabilities to apply for SSDI and SSI benefits.

Stapleton, Coleman, and Dietrich also provide strong, if indirect, evidence that recent changes in screening stringency played a central role in explaining program growth. Indeed, the very fact that award rates were rising at the same time that application rates were rising would seem to suggest an important role for changes in screening stringency. They find that changes in the unemployment rate, together with other factors they include in their models, could explain almost all of the growth in applications for impairments related to conditions of internal organs, but could account for much less of the growth in applications for impairments related to musculoskeletal or mental health conditions. These patterns suggest that regulatory changes such as the increased weight given to pain and other symptoms, the increased reliance on source evidence, and the broadening of the standards used for those with mental impairments all have contributed importantly to the recent surge in applications for SSI.

Whereas the 1990s recession seems to be part of the explanation for the rapid rise in applications for SSI benefits that occurred during the first part of the 1990s, no such rise occurred during the severe 
recession of the early 1980s. A reasonable interpretation of these patterns is that the tightening of eligibility standards that occurred during the early 1980s counteracted the effects of the 1980s recession. During the mid-1980s, when eligibility standards were relaxed again, the booming economy slowed any immediate response. However, when the 1990s recession hit, applications grew rapidly.

Researchers studying the increases in SSI caseloads have found evidence that an important factor explaining the growth in SSI over the 1990s has been efforts by states to shift individuals off state-funded programs such as general assistance and onto SSI. States that cut general assistance benefits experienced above-average growth in the application for SSI benefits (Lewin-VHI 1995a). Using monthly administrative data from Michigan, Bound, Kossoudji, and Ricart-Moes (1995) find that the increase in the application for SSI benefits exactly coincided with the end of general assistance in Michigan. However, they also find that general assistance benefits typically are less generous than are SSI benefits. This finding is surprising within the context of a simple labor supply model that ignores the relative costs of application for these two types of benefits. The fact that many potentially eligible people did not apply for the more generous SSI benefits suggests that applying for disability benefits may be difficult and onerous. There is also considerable anecdotal evidence that states and third parties often act as intermediaries to facilitate the SSI application process (Livermore, Stapleton, and Zeuschner 1998; Bound, Kossoudji, and Ricart-Moes 1998).

Brown, Hoyt, and Scott (1999) approach a similar question using county-level data on SSI and AFDC participation rates. They find that prior to 1996 welfare reform, variation in AFDC programs across states explains little of the variation in SSI participation. They also find that program and eligibility variables explain more of the county-to-county variation in SSI participation than in AFDC participation, suggesting that SSI is a more tightly targeted program than AFDC. Still, they conclude that given the significant changes in welfare programs embodied in the transition from AFDC to TANF, SSI participation rates likely will be affected. 
Increases in the value of Medicaid benefits for individuals on SSI also may have contributed to the recent growth in applications for both programs. Yelowitz (1998) uses cross-state variation in Medicaid benefits to estimate the effect of changes in their value on participation in SSI. In particular, in response to court orders, many states increased Medicaid benefits in 1991. Using these changes, Yelowitz estimates that increases in the value of Medicaid which occurred over the late 1980s and early 1990s can explain about 20 percent of the increase in the working-age population receiving SSI benefits.

However suggestive Yelowitz's results are, they do not seem to be very robust. Stapleton and his colleagues (Lewin-VHI 1995b) used Yelowitz's methodology to look at the effect of changes in the value of Medicaid on the application for SSI benefits and found no measurable effects. Given the expectation that increases in the value of Medicaid initially would have a proportionately bigger effect on the number of applications (a flow) than on the beneficiaries (a stock) this non-result is surprising. While it is hard to imagine that eligibility for Medicaid benefits does not make SSI more attractive, finding statistical evidence of this effect has proven to be quite challenging.

Effects of Work Incentives and Disincentives. Because the United States has few program alternatives that offer long-term benefits to working-age persons who are not working, the relatively generous benefits and imperfect screening mechanisms in SSI could pose significant work disincentives for persons with disabilities who are considering applying for benefits. Additionally, the high marginal tax rates for those on the program could discourage exit from it and entry into the labor force.

A large empirical literature has tried to estimate the magnitude of moral hazard effects. Some of that literature has examined the net effect of SSI (and SSDI) on labor force participation rates, such as how much higher participation rates would be were it not for these programs. However, this literature has primarily focused on estimating the disincentive effects of SSDI program parameters, benefit generosity, or screening stringency. For a complete review of this literature see Bound and Burkhauser (1999). While it is tempting to look to the SSDI literature to gain some insights into how the SSI 
program affects the behavior of low-income adults with disabilities, doing so is problematic. First, whereas both programs use the same inability to perform substantial gainful activity criteria with respect to establishing categorical eligibility, the benefit structures of the two programs are quite different. ${ }^{45}$ Second and perhaps more important, the typical SSDI applicant has much different socio-economic characteristics than the typical SSI applicant. SSI applicants and recipients are younger, are more likely to have functional limitations related to mental conditions, have lower household income, have less education, have fewer work skills and less experience in the marketplace, and are more likely to come from an ethnic or racial minority than are SSDI applicants and recipients.

The empirical research on the work disincentives of welfare programs consistently finds that recipients are unresponsive to changes in marginal tax rates (for reviews of this literature see Moffitt, 1986 and Hoynes and Moffitt, 1996). This literature provides little evidence that individuals participating in means-tested programs respond to financial incentives by working more. Research on the extent to which individuals with disabilities have the same income and substitution elasticities of participants in other programs would be an important step in determining whether the results discussed are applicable to the SSI population.

The small amount of research that does exist on the work efforts of SSI recipients suggests that, despite special allowances for SSI recipients who receive earnings (e.g., 1619(a) and (b) status), only a small percentage of disabled adult SSI recipients work. ${ }^{46}$ In 1976 only 3.4 percent of all disabled adult

${ }^{45}$ For example, SSDI is an insurance-based (non-means-tested) program with its benefits based on past individual earnings history, while SSI is a flat rate means-tested welfare program. SSDI provides recipients Medicare benefits after they are on the program two years and restricts its recipients to labor earnings up to $\$ 750$ per month for a limited period, after which they face a significant program "notch" and lose all SSDI benefits. SSI provides it recipients with immediate access to Medicaid and, once on the program, allows them more generous work options compared to SSDI.

${ }^{46}$ Section 1619 (Public Law 96-265) became law in 1986. These provisions dramatically altered the earnings opportunities for SSI disabled adults. Section 1619(a) allows recipients to maintain their SSI (and Medicaid) benefits even when their earnings exceed SGA. Section 1619(b) extends Medicaid coverage to workers whose earnings make them ineligible for SSI cash payments. 
beneficiaries worked. Since that time, the percentage of disabled SSI recipients with earnings has nearly doubled but, at 6.2 percent, remains quite low. A somewhat more optimistic picture comes from work by Muller, Scott, and Bye (1996), looking at the work history of SSI recipients. They find that among a sample of SSI beneficiaries coming onto the rolls between 1976 and 1988, approximately one-quarter worked during the time they received benefits.

In response to the low number of SSI recipients who work, the Social Security Administration has conducted two large-scale return-to-work demonstration projects to study the effectiveness of providing rehabilitation and employment services to SSI beneficiaries. The first, the Transitional Employment Training Demonstration (TETD) project, which operated between 1985 and 1987, focused on SSI beneficiaries whose primary condition was mental retardation. The second, Project Network, operated between 1992 and 1995 and included SSDI and SSI beneficiaries with a wide range of diagnoses. The two demonstration projects were run in a similar fashion. Eligible beneficiaries in selected cities were invited to participate in the two projects. Volunteers were then randomly assigned to treatment and control groups. The treatment groups were provided with rehabilitation and employment services, while the control group was not. Using both survey and administrative data, the effectiveness of the rehabilitation and employment services could then be studied by comparing outcomes of the experimental and control groups.

Analysis of the impact of the TETD project suggests that the employment and rehabilitation services provided to SSI beneficiaries significantly increased earnings for participants over the six years they were observed (earnings of the treatment group were close to 70 percent higher than the control group (roughly $\$ 4,000$ in 1996 dollars) but the program only had a small impact on average SSI payments (\$870 per participant). This small reduction in SSI payments was not nearly sufficient to cover the average costs of transitional employment services for program participants (Thornton and Decker 
1989). ${ }^{47}$ However, when the employment and earnings gains for program participants are weighed against the costs of providing the employment services, the program may very well have produced a net social benefit. Similar results were obtained from Project Network. Analyses of the program (Kornfeld and Rupp 2000) show that during the first two years of operation Project NetWork produced modest net benefits to persons with disabilities, as earnings gains among participants more than offset reductions in SSI and SSDI benefits. However, the small gain in earnings was not nearly sufficient to offset the costs of administering Project NetWork. Moreover, data for a third year follow up on about 70 percent of the sample show earnings gains declined to about zero, suggesting that the increase in earnings may have been temporary.

Importantly, in both cases the fraction of program eligibles who volunteered for either TETD or Project Network was small—roughly 5 percent in each experiment. This suggests that, however beneficial it might be to those who participate, the provision of transitional employment services to those on SSI who volunteer for services is unlikely to have much of an impact on the overall SSI population. This is hardly surprising. Beneficiaries go through a long process to establish that they have medical conditions that prevent them from performing substantial gainful activity. At least at the time they apply for SSI benefits, applicants would appear to have put substantial energy into becoming eligible for program benefits—-benefits that must more than compensate applicants both for any loss of income associated with moving onto SSI as well as for the costs associated with applying for benefits. ${ }^{48}$ For the great majority of those awarded benefits, their health is unlikely to improve over time and their labor

\footnotetext{
${ }^{47}$ The net effect of the transitional employment services is harder to evaluate and depends crucially on the extent to which the services provided by the project substitute for other services paid for by the government (Thornton and Decker 1989).

${ }^{48}$ As will be discussed later in this chapter, the cost of applying for SSI disability benefits for the average applicant may be lower today than in previous periods. To the extent that welfare reform has changed the SSI applicant pool, individuals may not be making a choice between work and benefits but rather between other welfare and SSI. Moreover, in response to both welfare reform and state financing issues, state governments may engage in more SSI outreach and lower the applicant's cost of applying.
} 
market opportunities are probably deteriorating. Moreover, those who return to work may be subject to high marginal tax rates. ${ }^{49}$ Under such adverse conditions it is not surprising that voluntary returns to work are rare.

\section{SSI and Families of Children with Disabilities}

As noted earlier, the primary justification for awarding cash benefits to poor families containing a disabled child is that the families of disabled children face additional economic burdens associated with their child's poor health (see NASI 1996). These economic burdens may include lost earnings from a parent who provides care for the disabled child and medical and nonmedical expenses related to the child's specific disability. However, SSI child benefits are not based on an earnings replacement or expenditure offset formula, but, rather are means-tested against current income. It is difficult to know a priori whether beneficiary families experience dramatic drops in labor earnings or increases in net-ofdisability-expenditures in family income. In fact, it is equally possible that recipient families have low incomes prior to the onset of the child's disability, and that the additional burdens placed on families with a disabled child are not the root cause of their current financial situation.

As with the adult SSI program, the child SSI program faces the problems related to moral hazard-incentives for parents to have their children become and remain eligible for SSI. The degree to which this potential moral hazard causes behavioral changes with respect to gaining and maintaining eligibility depends, to some degree, on the pre-disability economic circumstances of the covered families. If the typical family is a middle-income family that experiences a dramatic decline in their economic well-being at the onset of their child's disability, but in all other ways has the market and social characteristics necessary to attain middle-income status, then cash programs that only partially offset

\footnotetext{
${ }^{49}$ The evidence we have on the extent of work activity by those who have been awarded SSI benefits comes mostly from the analysis of Social Security Earnings data. Anecdotal evidence suggests that some fraction of those on SSI are actually working, but are working "off the books." Research targeted on such "off the books" work by SSI beneficiaries along the lines of that done by Edin and Lein (1997) on welfare recipients would be valuable.
} 
these losses are unlikely to lead to major disincentives for labor market participation or the child's recovery. However, if the typical family that comes onto the SSI rolls is already economically vulnerable (e.g., family members have few market skills, one-parent family, etc.) prior to the onset of their child's disability, eligibility for SSI is likely to have much greater economic importance. Poor families who have a child with a disability may be able to completely replace or even increase their family income if their child's disability results in the receipt of SSI benefits. Thus, pre-disability differences in economic well-being alter the replacement rate of SSI among families of children with disabilities and make the moral hazard of behavioral change much greater among pre-disability low income families than among middle- or high-income families.

Factors Affecting SSI Participation. As is true for the adult disability determination process, the disability determination process for children has undergone substantial revision. As noted earlier, the most important change came in 1990 when the Supreme Court required SSA to significantly broaden the eligibility criteria for childhood disability. The same year as the Zebley decision, the SSA also released regulations revising the procedures used to evaluate mental impairments among children. The new rules expanded SSA's medical listings for childhood mental impairments by adding such illnesses as attention deficit hyperactivity disorder (ADHD) and by incorporating functional criteria in the listings. Similar to the changes made in the adult process, the SSA modified the types of evidence used to judge the damage of mental illness; less emphasis was placed on the testimony of medical professionals and more weight was given to the information parents, teachers, and counselors provided about the child's condition. As with the Individual Functional Assessment (IFA), the new mental impairment regulations focused on how disabilities affected a child's performance in school.

Following these changes the child SSI caseloads grew rapidly. Data from the Social Security Administration show that between 1989 and 1996, the number of children under 18 receiving SSI more than tripled, from 265,000 to 955,000. Applications increased from 132,000 in 1989 to 541,000 per year 
in 1994, and awards more than quadrupled. The yearly allowance rate on applications rose from 39 percent in 1989 to a peak of 58.1 percent in 1992. In 1992, the number of children on SSI grew by 40 percent (GAO 1998).

In response to rapid caseload growth and a burgeoning concern that the disability determination process was allowing too many children without serious medical problems onto the disability rolls, Congress narrowed the criteria for childhood disability in 1996. In addition, Congress mandated SSA to redetermine the eligibility of children on the rolls who might not meet the new eligibility criteria because they received benefits on the basis of the former, more lenient, standards. ${ }^{50}$ In 1997 , the number of SSI recipients under age 18 fell by 7.9 percent and increased only slightly in 1998 .

Economic factors also influence the decision of families to participate in SSI. Evidence suggests that a large fraction of the children coming onto the rolls in the 1990s previously participated in the AFDC program. Daly and Burkhauser (1998), using data from the National Longitudinal Survey of Youth (NLSY), calculate that two-thirds of children found eligible for SSI in the early 1990s were in families already receiving some type of welfare assistance. Other things equal, families eligible for multiple programs are likely to select those programs that provide the highest net benefit to them. Although additional costs are associated with SSI (e.g., more stringent application rules, greater stigma related to receiving benefits, etc.), as the benefit difference between SSI and other programs increases, more families will be willing to incur these costs to improve their economic situation.

Kubik (1999) tests the empirical significance of this prediction. He finds that AFDC recipient families who successfully qualify a child for SSI benefits can increase family income substantially. Table 10 (taken from Kubik, 1999) shows how a family's income can change when a child moves from AFDC to SSI. The analysis is for two states, Maryland and Connecticut, and demonstrates two points:

${ }^{50}$ SSA originally identified 288,000 children as potentially affected by changes in the eligibility criteria. In 1998, SSA scaled back their estimates; new estimates suggest that fewer than 100,000 children will become ineligible for SSI (GAO 1998). 
(1) families can significantly improve their economic well-being if someone in the family qualifies for SSI; and (2) the generosity of SSI relative to AFDC has grown over time, implying that the incentive to transfer to the SSI program has grown. Table 10 shows that a family of three living in Maryland in 1990 could have increased monthly family income by over $\$ 3,500$ if one child transferred to the SSI rolls. By 1994 , this advantage had grown to almost $\$ 4,400$. Since other in-kind benefits, such as Medicaid and Food Stamps remained constant, the family experienced a net gain in income if the child moves from AFDC to the SSI rolls.

A small number of empirical papers have examined the responses of AFDC participants to changes in the SSI program, including the post-Zebley broadening of the childhood disability criteria, and increases in the relative generosity of SSI benefits during the 1990s (see Rand (1998) for a thorough review of this literature). Garrett and Glied (2000) examine the impact of the Zebley decision on SSI and AFDC caseloads using the Zebley ruling as a "natural experiment," representing an exogenous increase in the supply of SSI benefits (i.e., eligibility criteria are relaxed and more families are allowed onto the SSI program). They exploit the state-level variation in the difference between SSI and AFDC payments to test whether families are responsive to increases in net benefits. Their findings suggest that families are responsive to differences in program generosity. They found that in low AFDC states, where the difference between AFDC and SSI payments would be largest, about 53 percent of the new post-Zebley child SSI cases switched from the AFDC program; nationally, only about 43 percent of new SSI child cases came from the AFDC program.

Along the same lines, Kubik (1999) examines the incentives for families to identify children as disabled when SSI benefits are more generous than AFDC benefits. Using data from the National Health Interview Survey (NHIS) and changes in the difference in SSI and AFDC benefits, Kubik finds that reported disabilities_-particularly mental impairments — were higher in low AFDC benefit states than in 
high AFDC benefit states. ${ }^{51}$ Using data from the Current Population Survey on household SSI receipt, he also finds that relatively generous SSI benefits (relative to AFDC payments) affect SSI participation. Kubik estimates that a 10 percent increase in SSI benefit generosity increases the probability of SSI participation among families with low education by 0.39 percentage point—a five percent increase in SSI participation. Overall, Kubik finds a significant and positive relationship between the marginal value of SSI benefits and the prevalence of disability, and receipt of SSI, among children.

Effects of SSI on Work Effort of Families. SSI support for families potentially affects the labor market effort of parents. However, there is not a large empirical literature on this relationship. Garrett and Glied (2000) estimate that the Zebley decision had a significant impact on the employment of unmarried women without a high school education. Kubik (1999) finds similar results; examining behavior after Zebley, Kubik finds that increases in SSI benefits lowered the probability that loweducation household heads work. He estimates that a 10 percent increase in SSI benefits decreases labor force participation of low-education household heads by about 2 percent. The empirical evidence on the effects of SSI benefit levels on parental work effort after Zebley suggest that, in addition to responding to the particular health needs of a child, mothers also respond to the income effect present in the guarantee as well as to the high marginal tax rates placed on their labor earnings.

\section{SSI and the Behavior of the Aged}

Factors Affecting Participation. Researchers have offered a number of hypotheses to explain the low enrollment in SSI among the elderly, including lack of knowledge about the program and eligibility criteria, prohibitively expensive application costs (e.g., time cost or cost of learning), and unobserved costs of receiving benefits (e.g., welfare stigma). Early work on this topic focused primarily on the roles

\footnotetext{
${ }^{51}$ To account for state-specific factors that may affect the prevalence of disability, Kubik examines this relationship before and after Zebley. Thus, he measures the change in the prevalence of reported disability and compares it to the change in the difference between SSI and AFDC benefits by state.
} 
of welfare stigma and program knowledge on the decision to apply. Coe (1985) reported that of the SSI nonparticipants classified as eligible (48 percent of all eligible individuals), a significant fraction were not aware of the program or did not think they were eligible. Coe also found that benefit levels were positively and significantly related to participation, with each $\$ 10$ in additional benefits resulting in a 2.4 percentage point increase in the probability of participation. This is consistent with the notion that relatively high benefit levels would outweigh any noninformational barriers to participation, such as access costs. However, Coe notes, noninformational barriers accounted for only 25 percent of the negative effect of low benefits on participation. The primary reason lower benefit levels decreased participation was that eligible individuals facing low benefit levels were more likely to believe that they were not eligible to participate. Warlick (1982) also concluded that program information and the difficulty of the application process were the primary reasons for low participation rates among the eligible elderly.

Recent work by McGarry (1996) draws a slightly different conclusion. McGarry extends previous research by using detailed asset and income information from the 1984 SIPP to more accurately classify eligibility by accounting for differences in benefit levels introduced by state supplementation, and by explicitly controlling for measurement error in the estimation process. McGarry concludes that the participation decision is primarily determined by the financial situation of eligible individuals. She finds that although all persons eligible for SSI are poor, the probability of participation declines as the number of alternative resources increases. Similar to Coe, she finds that the elasticity of the expected benefit is about 0.5 and that, after controlling for size of the SSI payment, those with greater resources are less likely to participate. ${ }^{52}$

\footnotetext{
${ }^{52}$ Coe's measure of other resources includes only the home ownership variable. McGarry uses a more extensive set of resource measures, including home and other asset ownership, labor earnings over the year, and income-to-needs ratio.
} 
McGarry departs from previous research in finding little evidence that welfare stigma or informational program costs affect participation. However, as she notes, her results must be interpreted with caution. The estimated model is a reduced-form version, which includes variables likely to affect participation through more than one path. If a variable operates in opposite directions on different factors, its importance may be obscured. Thus, while she argues that the negative coefficient on years of schooling implies that lack of information does not deter participants, this result can just as easily be interpreted as evidence of stigma associated with receiving benefits (e.g., more educated individuals feel more stigma associated with receiving benefits).

In general, the low SSI participation rates among the elderly remain somewhat of a mystery. Although there is reason to believe that some individuals are uninformed about the program or their eligibility for benefits, there is not much evidence that a large fraction of the elderly poor in need of assistance are constrained by transactions costs. What does appear to be the case is that eligible individuals who are close to the margin on the means test are less likely to participate in the program. As Coe (1985) argued, this may be due to individuals misunderstanding the income disregards and other program rules that determine eligibility. Thus, unless individuals are sufficiently below the means test guidelines, they believe that they will be ineligible, and thus, do not apply. This interpretation is consistent with McGarry's simulation of responses given a change in benefit levels. McGarry examined how raising the federal income guarantee to the U.S. poverty line impacted the participation of those previously, and newly eligible for benefits. She finds that raising the benefit level increases the participation rates of those previously eligible by 16.5 percentage points, from 0.534 to 0.699 . In contrast, she finds that less than 30 percent of those newly eligible under the increased income limit participate in the program.

Savings Behavior. Although it is well recognized that means-tested programs create incentives for potentially eligible individuals to alter their behavior to ensure qualification, few studies have 
rigorously reviewed the incentives facing elderly individuals close to the age and resource tests for SSI. Yet, it is likely that SSI program features create disincentives for working and saving as individuals approach the age of eligibility. Neumark and Powers (1998) focus on the relation between saving behavior and SSI receipt among the elderly. They argue that SSI's influence on the savings patterns of elderly individuals should vary with the expected level of their benefits and the likelihood of receiving them. In practice, individuals with low lifetime earnings living in high-benefit states should reduce saving more than high lifetime earners living in low-benefit states. Neumark and Powers use state-level variation in the generosity of supplemental SSI payments to identify the effects of SSI on the savings behavior of the elderly. They find that SSI reduces the saving of men and women nearing the age of retirement who are likely participants in the program.

\section{Future Challenges}

\section{Changing Demand for Benefits}

Although SSI is an income maintenance program narrowly targeted on the aged, blind, and disabled, many of those eligible for SSI also are eligible for other transfer programs. Program interactions and the behavioral incentives such interactions produce depend in large part on the size of the group eligible for multiple programs and on the fluidity of boundaries defining who is and who is not eligible. When the dividing lines separating the working-age adult and child populations eligible for SSI from those eligible for other income-based benefits are imprecise, as with disability, policy changes in other welfare programs likely will affect SSI caseloads.

Our review of the literature provides some evidence that families of adults and children with disabilities are moving from other welfare programs to SSI. Table 11 documents the prevalence of various income sources among the poor and shows that as the receipt of public welfare benefits has declined, receipt of SSI has increased. This has occurred for both households of children under age 18 and adults age 18-64. Poor households increasingly are relying on SSI for some portion of their income. 
Moreover, as shown in Table 6, for adults age 18-64, the increase in SSI receipt has occurred without a change in the prevalence of self-reported disability.

With respect to the aged population, the expansion of private pensions and social security coverage significantly reduced the number of older persons receiving SSI benefits (Table 11). However, this pattern may not hold in the future. The normal retirement age for receiving social security benefits is scheduled to increase from 65 to 67 over the next 15 years and financial pressures on the Social Security system may lead to further increases in the normal retirement age or to reductions in benefit levels. To the degree that OASI benefits for older persons are diminished it is likely to produce increased demand for SSI benefits.

\section{Permanent versus Temporary Support}

As the population on SSI changes and the group of those not expected to work narrows, the structure of SSI comes into question. As we have shown, the SSI population has dramatically shifted over time. It is now dominated by children and young adults with disabilities. To date, despite some attempts to offset the negative work incentives in SSI-Section 1619—exits from SSI to employment, even among this younger population, have been rare. As shown earlier in this chapter, for individuals and families receiving SSI and other transfer program benefits the marginal tax rates can go from 50 to near 100 percent at relatively low earnings levels. While such high tax-rates and relatively generous guarantees make sense for populations not expected to work, in a population where work is possible,

they seriously discourage work. Hence, for those with a capacity to work, SSI, together with eligibility for other programs, can become the "poverty trap" that the original supporters of Nixon's single universal FAP program were trying to avoid. The work disincentives embodied in SSI will soon be highlighted by the nearly one million post-Zebley children who are now on the SSI-children rolls. Given the broad commitment to integrating people with disabilities into the workforce that led the to enactment of the 
ADA and other pro-work programs in the 1990s, major initiatives to integrate these children into the workforce rather than onto adult SSI-disability rolls likely will be considered.

\section{Summary and Conclusions}

The enactment of the Supplemental Security Income program in 1972 was the culmination of a four-year debate over a much more overarching welfare reform—a federally-funded minimum income guarantee for all Americans. Unlike Nixon's FAP proposal, SSI was targeted on the sub-group of lowincome individuals "not expected to work." Since then, SSI has grown dramatically. Moreover, the composition of SSI beneficiaries has changed and in 1999 was dominated by adults and children with disabilities.

How one views the increases in the SSI disability population largely is influenced by one's view of the social purpose of SSI. For those who see SSI as an incomplete substitute for a universal guaranteed income program like the NIT, expansions in the SSI program are seen as appropriate because they bring the United States more into line with most Western European countries that provide such a universal minimum social safety net for all their citizens. However, for those who are worried about the long-term effects of a life-time on government transfers, the rise in the prevalence of disability transfer recipients-particularly among poor children and younger adults—is of more concern.

Support for civil rights-based legislation like the ADA, for instance, is based on the idea that people with disabilities should have equal access to employment. Supporters of this type of legislation view unequal access to jobs to be a greater impediment to employment than a health impairment. Furthermore, they ask that social policy focus on altering workplace institutions to more fully accommodate people with disabilities. Hence, in a world of full accommodation, they argue the disability-transfer population should be zero. Fundamentally, the current policy debate over expanding SSI transfer rolls hinges on the role people with disabilities should play in society. Should people with disabilities be expected to work or not? If yes, then policies targeting people with 
disabilities — particularly the young — would be better focused on education, rehabilitation, job training, and accommodation than on increasing or expanding transfers. Likewise, for children with disabilities, investing more time, energy, and resources toward enhancing their education and development, rather than focusing solely on supplementing the income of their households, might be more desirable.

Two factors are likely to cause the debate surrounding SSI to intensify over the next decade. First, the protracted period of economic growth that the United States has experienced since 1992 cannot last forever. And, as we have shown, applications for SSI are sensitive to the business cycle. A downturn in the economy will increase applications and heighten efforts to broaden the categorical definition of disability. This will be even more the case since the welfare reforms of 1996 have made it less likely that low-income people will be eligible for other programs. Second, demographic forces are increasing the percentage of the population aged 50 and over. Given that the prevalence of disability rises sharply at these ages, applications for SSI likely will rise. These demographic changes are magnified by the fact that in 2000 , the age of full eligibility for social security retirement began to increase to age 67 . The increase in the normal retirement age will increase the relative value of SSI benefits for those who wish to leave the labor market prior to age 67.

In general, our examination in this chapter suggests that in the absence of a universal guaranteed income program for all Americans, the operational flexibility of the categorical eligibility criteria for SSI has made the program sensitive to both downturns in the business cycle and to increases in the pool of vulnerable people. Recent legislative changes and ongoing demographic movements suggest that another major round of program expansion is likely in the future. 


\section{References}

Aarts, L., R.V. Burkhauser, and P.R. de Jong. 1996. Curing the Dutch Disease: an International Perspective on Disability Policy Reform. Aldershot, UK: Avebury.

Black, D., K.Daniel, and S. Sanders. 1998. "The Impact of Economic Conditions on Participation in Disability Programs: Evidence from Coal Boom and Bust," UK Department of Economics Working Paper E-203-98. Lexington, KY: University of Kentucky.

Bound, J. and R.V. Burkhauser. 1999. "Economic Analysis of Transfer Programs Targeted on People with Disabilities." in the Handbook of Labor Economics, Volume 3(c), edited by O. Ashenfelter and D. Card. Amsterdam: Elsevier Science: 3417-3528.

Bound, J., S. Kossoudji, Ricart-Mous, G. 1998. "The Ending of General Assistance and SSI Disability Growth in Michigan: A Case Study." In Growth in Disability Benefits: Explanations and Policy Implications, edited by K. Rupp and D. Stapleton. Kalamazoo, MI: W.E. Upjohn Institute for Employment Research.

Bound, J., J.B. Cullen, and L. Schmidt. 2000. "The Welfare Implications of Increasing DI Benefit Generosity." University of Michigan, Ann Arbor: mimeo.

Burke, V.J. and V. Burke. 1974. Nixon's Good Deed: Welfare Reform. New York: Columbia University Press.

Burkhauser, R.V. and M.C. Daly. 1996. "Employment and Economic Well-Being Following the Onset of a Disability: The Role for Public Policy." In Jerry Mashaw, Virginia Reno, Richard V. Burkhauser, and Monroe Berkowitz (eds.), Disability, Work, and Cash Benefits. Kalamazoo, MI: W.E. Upjohn Institute for Employment Research, pp. 59-102.

Burkhauser, R.V., M.C. Daly, and A. Houtenville. Forthcoming. "How Working Age People with Disabilities Fared over the 1990s Business Cycle." In Insuring Health and Income Security for an Aging Workforce, edited by P. Budetti, R. Burkhauser, J. Gregory, and A. Hunt. Kalamazoo, MI: W.E. Upjohn Institute for Employment Research.

Burkhauser, R. V. and T. A. Finnegan. 1993. "The Economics of Minimum Wage Legislation Revisited." Cato Journal 13(1): 123-129.

Burkhauser, R. V. and T. A. Finnegan. 1989. "The Minimum Wage and the Poor: The End of a Relationship.” Journal of Policy Analysis and Management 8(1): 53-71.

Burkhauser, R.V., R.H. Haveman, and B.L. Wolfe. 1993. "How People with Disabilities Fare When Public Policies Change," Journal of Policy Analysis and Management, 12(2) (Spring): 251-269.

Burkhauser, R.V. and T.M. Smeeding. 1981. "The Net Impact of the Social Security System on the Poor." Public Policy, 29(2) (Spring): 159-178. 
Burkhauser, R.V. and D.C. Wittenburg. 1996. "How Current Disability Transfer Policies Discourage Work: Analysis from the 1990 SIPP," Journal of Vocational Rehabilitation, 7(1/2) (August): 927.

Coe, R. 1985. "Nonparticipation in the SSI Program by the Eligible Elderly." Southern Economic Journal. 51(3): 891-897.

Congressional Research Service. 1999. Cash and Noncash Benefits for Persons with Limited Income: Eligibility Rules, Recipient and Expenditure Data, FY 1996-FY1998. Report Code: RL30401. The Library of Congress: Washington DC.

Daly, Mary C. 1994. "The Economic Well-Being of Men with Disabilities: A Dynamic Cross-National View." Unpublished Ph.D. dissertation, Syracuse University.

Daly, M.C. and R.V. Burkhauser. 1998. How Family Economic Well-Being Changes Following the Onset of a Disability: A Dynamic Analysis. Syracuse University Manuscript.

Edin, K. and L. Lein. 1997. Making Ends Meet: How Single Mothers Survive Welfare and Low-Wage Work. New York: Russell Sage Foundation.

Friedman, M. 1962. Capitalism and Freedom. Chicago: University of Chicago Press.

Friedman, M. 1968. “The Case for a Negative Income Tax,” edited by M. Laird, Republican Papers, Paperback ed. Garden City, NY: Anchor.

Garrett, A.B. and S. Glied. 2000. "Does State AFDC Generosity Affect Child SSI Participation?" Journal of Policy Analysis and Management. 19(2): 275-295.

Giannarelli, L. and E. Stuerle. 1994. "It's Not What You Make, It's What You Keep: Tax Rates Faced by AFDC Recipients." Paper presented at the Meetings of the Association for Public Policy Analysis and Management, Chicago, October, 1994.

Hoynes, H. and R. Moffitt. 1996. "The Effectiveness of Financial Work Incentives in Social Security Disability Insurance and Supplemental Security Income: Lessons from Other Transfer Programs.” In J. Mashaw et. al. Disability, Work and Cash Benefits. Kalamazoo, MI. W.E. Upjohn Institute for Employment Research.

Hubbard, R. Skinner, J., and Zeldes, S. 1995. "Precautionary Saving and Social Insurance.” Journal of Political Economy, 103(2): 360-99.

Keane, M. And R. Moffitt. 1998. "A Structural Model of Multiple Welfare Program Participation and Labor Supply.” International Economic Review. 39(3), pp. 553-589.

Kornfeld, R. and K. Rupp. 2000. "The Net Effects of the Project NetWork Return-to-Work Case Management Experiment on Participant Earnings, Benefit Receipt, and Other Outcomes. Social Security Bulletin, 63(1): 12-33. 
Kubik, J. 1999. "Incentives for the identification and treatment of children with disabilities: the supplemental security income program." Journal of Public Economics. 73: 187-215.

Lando, M. E., R. Cutler, and E. Gamber. 1982. 1978 Survey of Disability and Work: Data Book. Washington, DC: U.S. Government Printing Office.

Laplante, M.P. 1991. “The Demographics of Disability," in J. West, ed., The Americans with Disabilities Act: From Policy to Practice. Milbank Memorial Fund: New York.

Lewin-VHI. 1999. "Policy Evaluation of the Overall Effects of Welfare Reform on SSA Programs." Final Report and Appendix. Washington, DC: The Office of the Assistant Secretary for Planning and Evaluation, U.S. Department of Health and Human Services and the Social Security Administration

Lewin-VHI. 1995a. "Labor Market Conditions, Socioeconomic Factors and the Growth of Applications and Awards for SSDI and SSI Disability Benefits." Final Report. Washington, DC: The Office of the Assistant Secretary for Planning and Evaluation, U.S. Department of Health and Human Services and the Social Security Administration.

Lewin-VHI. 1995b. "Longer-Term Factors Affecting SSDI and SSI Disability Applications and Awards." Final Report. Washington, DC: The Office of the Assistant Secretary for Planning and Evaluation, U.S. Department of Health and Human Services and the Social Security Administration.

Library of Congress. 1998. "Vocational Factors in the Social Security Disability Decision Process: A Review of the Literature." Report prepared under an Interagency Agreement for the Social Security Administration Office of Disability Research. The Federal Research Division Library of Congress.

Livermore, G., D.C. Stapleton, and A. Zeuschner. 1998. "Lessons from Case Studies of Recent Program Growth in Five States." In Kalman Rupp and David C. Stapleton (eds.), Growth in Disability Benefits: Explanations and Policy Implications. Kalamazoo, MI: W.E. Upjohn Institute for Employment Research.

Mashaw, J.L. and V.P. Reno. 1996. Balancing Security and Opportunity: The Challenge of Disability Income Policy. Report of the Disability Policy Panel. Washington, DC: National Academy of Social Insurance.

McGarry, K. 1996. Factors determining participation of the elderly in SSI. Journal of Human Resources 31(12), 331-358.

Menefee, J., B. Edwards, S. Schieber. 1981. "Analysis of Nonparticipation in the SSI Program.” Social Security Bulletin, 44(6): 3-21.

Moffitt, R. 1986. "Work Incentives in Transfer Programs (Revisited) A Study of the AFDC Program.” Research in Labor Economics 8(b): 389-439. 
Muller, S., C. Scott, and B. Bye. 1996. Labor-force Participation and Earnings of SSI Disability Recipients: A Pooled Cross-Sectional Time Series Approach to the Behavior of Individuals. Social Security Bulletin 59(1), pp. 22-42.

Nagi, S. 1965. "Some Conceptual Issues in Disability and Rehabilitation.” In M.B. Sussman (ed.), Sociology and Rehabilitation. Washington, DC: American Sociological Association.

Nagi, S. 1969a. Disability and Rehabilitation: Legal, Clinical and Self-Concepts of Measurement. Columbus: Ohio State University Press.

Nagi, S. 1969b. "Congruency in Medical and Self-Assessment of Disability," Industrial Medicine and Surgery, 38: 27-36.

Nagi, S. 1991. "Disability Concepts Revisited: Implications to Prevention." In A.M. Pope and A.R. Tarlove (eds.), Disability in America: Toward a National Agenda for Prevention. Washington, DC; National Academy Press.

National Academy of Social Insurance. 1995. "Restructuring the SSI Disability Program for Children and Adolescents." Report from the Committee on Childhood Disability to the Disability Panel of the NASI. Washington, DC: NASI.

National Research Council. 2000. Survey Measurement of Work Disability. Division of Health Care Services, Institute of Medicine and Committee on National Statistics, National Research Council. Washington, DC: National Academy Press.

Neumark, D. and E. Powers. 1998. "The effect of means-tested income support for the elderly on preretirement saving: evidence from the SSI program in the US." Journal of Public Economics. 68(2): 181-206.

Parrott, T., L. Kennedy, and C. Scott. 1998. Noncitizens and the SSI Program. Social Security Bulletin, 61(4): 3-31.

Ponce, E. 1996. “State Optional Supplementation of SSI Payments, 1974-1995.” Social Security Bulletin, 59(1): 52-66.

Rand. 1998. "Background and Study Design Report for Policy Evaluation of the Effect of the' 1996 Welfare Reform Legislation on SSI Benefits for Disabled Children.” Washington DC. Social Security Administration.

Shields, J.F. , B. Barnow, K. Chaurette and J. Constantine. 1990. "Elderly Persons Eligible for and Participating in the Supplemental Security Income Program." Final Report prepared for the U.S. Department of Health and Human Services.

Smeeding, T. 1994. "Improving Supplemental Security Income." Social Welfare Policy at the Crossroads, edited by Robert Friedland, Lynn Etheridge, and Bruce Viadeck.

Social Security Administration. 1998. Annual Report of the Supplemental Security Income Program. Washington, DC: U.S. Government Printing Office. 
Social Security Administration. 1997. The Definition of Disability for Children. SSA Publication Number 05-11053.

Social Security Administration. Annual Statistical Supplements to the Social Security Bulletin, 19751999. Washington, DC: U.S. General Printing Office.

Stapleton, D.C., K.A. Coleman, K.A. Dietrich, and G.A. Livermore. 1998. "Empirical Analyses of DI and SSI Application and Award Growth." In Kalman Rupp and David C. Stapleton (eds.), Growth in Disability Benefits: Explanations and Policy Implications. Kalamazoo, MI: W.E. Upjohn Institute for Employment Research: 31-92.

Stigler, G. 1946. “The Economics of Minimum Wage Legislation,” American Economic Review 36(June): 358-65.

Thornton, Craig V. and Paul T. Decker. 1989. "The Transitional Employment Training Demonstration: Analysis of Program Impacts.” Princeton, NJ: Mathematica Policy Research. Project Report, July.

Tobin, J. 1968. "Raising the Incomes of the Poor," in K. Gordon, ed., Agenda for the Nation. Washington: Brookings Institution.

U.S. General Accounting Office, 1994. Rapid Rise in Children on SSI Disability Rolls Follows New Regulations. GAO/HEHS-94-225.

U.S. General Accounting Office. 1995. New Functional Assessments for Children Raise Eligibility Questions. GAO/HEHS-95-66.

U.S. General Accounting Office. 1998. SSA Needs a Uniform Standard for Assessing Childhood Disability. GAO/HEHS-98-123.

U.S. House of Representatives, Committee on Ways and Means. 1971. Social Security Amendments of 1971 (House Report No. 92-231). Washington, DC: U.S. Government Printing Office.

U.S. House of Representatives, Committee on Ways and Means. 1998. Background Material on Data and Programs within the Jurisdiction of the Committee on Ways and Means. Washington, DC: U.S. Government Printing Office.

Warlick, J. L. 1982. "Participation of the Aged in SSI.” Journal of Human Resources, 17(2): 236-260.

Weathers, R. 1999. "Essays in Applied Microeconomics.” Unpublished Ph.D. Dissertation. Syracuse University, December.

Wittenburg, D.C. 1997. “Three Essays on Public Policy Simulations.” Unpublished Ph.D. dissertation, Syracuse University, August.

Yelowitz, A. 1998. "Why did the SSI-disabled program grow so much?" Disentangling the effect of Medicaid." Journal of Health Economics, 17(3): 321-49. 
Table 1. Major Legislation and Reforms Affecting SSI Eligibility and Benefits, 1977-1999

\begin{tabular}{|c|c|}
\hline Legislation & Provisions \\
\hline 1976 & $\begin{array}{l}\text { - Excluded value of home from calculation of countable resources regardless of value of } \\
\text { home. }\end{array}$ \\
\hline 1976 & - $\quad$ Terminations without medical improvement \\
\hline 1976 & - $\quad$ Substantial Gainful Activity level (SGA) set at $\$ 230$ \\
\hline 1977 & $\begin{array}{l}\text { Excluded food stamps, federally donated food, and the value of free or reduced price } \\
\text { food for women and children under the Child Nutrition Act and National School Lunch } \\
\text { Act from calculation of countable unearned income. }\end{array}$ \\
\hline 1977 & - $\quad$ SGA set at $\$ 240$ \\
\hline 1978 & - $\quad$ SGA set at $\$ 260$ \\
\hline 1979 & $\begin{array}{l}\text { - Increased reasonable value for automobile to } \$ 4,500 \text { and reasonable value for personal } \\
\text { goods and household effects to } \$ 2,000 \text { of equity value. }\end{array}$ \\
\hline 1979 & $\begin{array}{l}\text { - Regulations comparing residual functional capacity (RFC) and vocational factors (age, } \\
\text { education, and work experience). }\end{array}$ \\
\hline 1979 & - $\quad$ SGA set at $\$ 280$ \\
\hline $\begin{array}{l}\text { Social Security Disability Amendments of } 1980 \\
\text { (PL 96-265) }\end{array}$ & 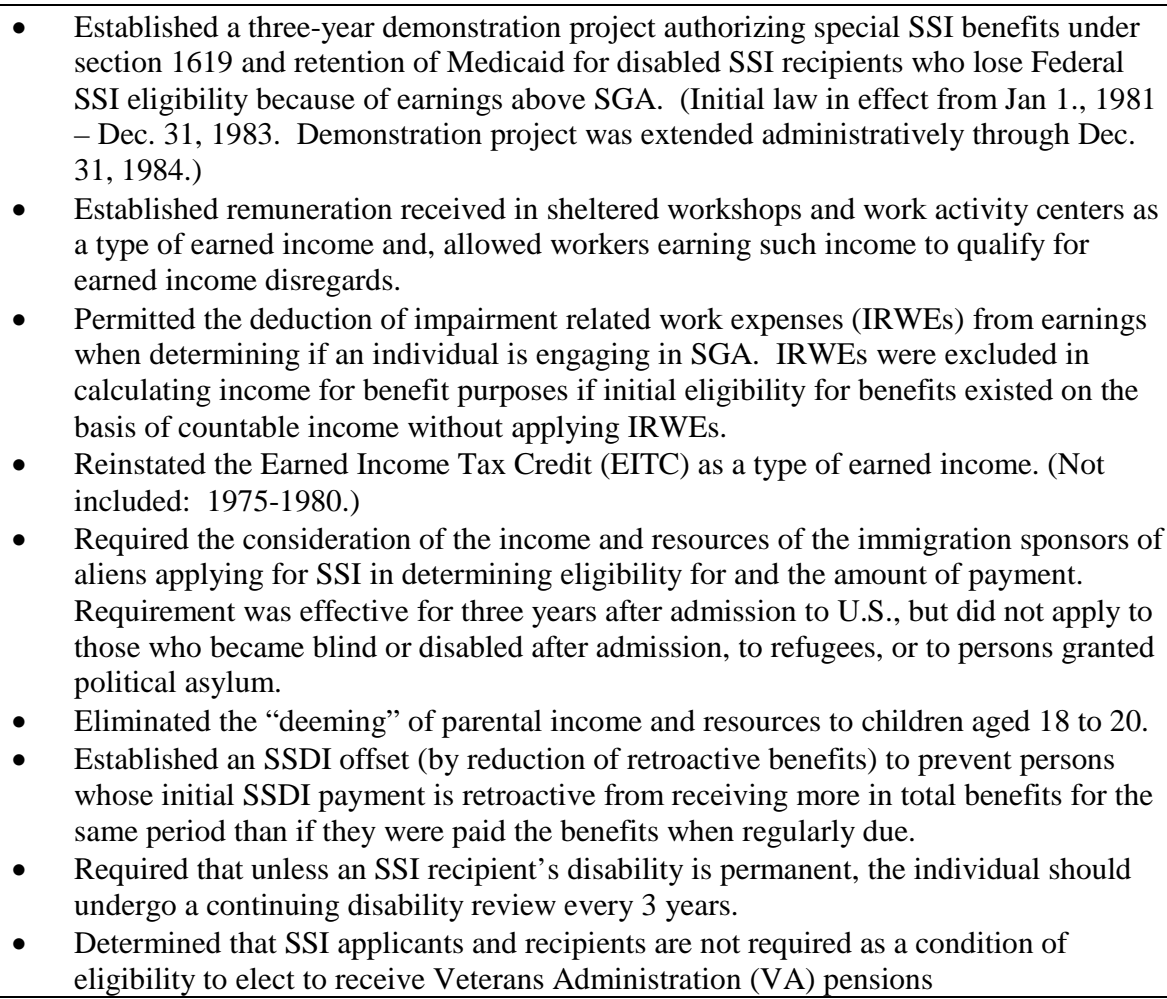 \\
\hline 1980 & - $\quad$ SGA set at $\$ 300$ \\
\hline $\begin{array}{l}\text { Omnibus Budget Reconciliation Act of } 1981 \\
\text { (PL 97-35) }\end{array}$ & $\begin{array}{l}\text { - Changed reference period for income, resources, and other criteria used in determining } \\
\text { eligibility and benefit amount from a calendar quarter to a month. }\end{array}$ \\
\hline
\end{tabular}


Table 1. (Continued)

\begin{tabular}{|c|c|}
\hline $\begin{array}{l}\text { Legislation } \\
\end{array}$ & Provisions \\
\hline $\begin{array}{l}\text { Social Security Amendments of } 1983 \\
\text { (PL 98-21) }\end{array}$ & $\begin{array}{l}\text { - Allowed payments to residents of public emergency shelters for the homeless for up to } \\
3 \text { months in any 12-month period. } \\
\text { Allowed for the disregard of support and maintenance provided in kind by a non-profit } \\
\text { organization or in cash or in kind by certain providers of home energy when } \\
\text { determining countable income if the State determines that the assistance is based on } \\
\text { need. } \\
\text { Allowed for the exclusion of certain home energy assistance payments from countable } \\
\text { income if a State agency certified that the assistance is based on need. }\end{array}$ \\
\hline $\begin{array}{l}\text { Disability Benefits Reform Act of } 1984 \\
\text { (PL 98-460) }\end{array}$ & $\begin{array}{l}\text { - } \quad \text { Required that the combined effects of an individual's multiple impairments be weighed } \\
\text { when making the disability determination. } \\
\text { Established a medical improvement standard and allowed for the termination of SSDI } \\
\text { and/or SSI benefits if there is substantial evidence that a person's medical condition has } \\
\text { improved and that he or she is able to work. } \\
\text { - Ordered the development of new mental impairment standards and placed moratorium } \\
\text { on mental impairment reviews until revised criteria were published. (Revised criteria } \\
\text { were published in 1985.) } \\
\text { - Required that evidence provided by a claimant's own physician be considered prior to } \\
\text { the results of an SSA consultative examination. } \\
\text { Extended special SSI benefits and retention of Medicaid for disabled SSI recipients } \\
\text { who lose Federal SSI eligibility because of earnings above SGA under section } 1619 \\
\text { through June 30, } 1987 \text {. } \\
\text { Expanded SSDI offset provision to allow for reduction of retroactive SSI benefits and } \\
\text { to apply in cases of SSDI benefit reinstatement. } \\
\text { Raised the limit on countable resources by } \$ 100 \text { a year for individuals and } \$ 150 \text { a year } \\
\text { for couples, beginning in calendar year } 1985-1989 \text {. Individual limit increased from } \\
\$ 1,500 \text { to } \$ 2,000 \text {, and limit for couples increased from } \$ 2,250 \text { to } \$ 3,000 \text { between } 1985 \\
\text { and } 1989 \text {. }\end{array}$ \\
\hline $\begin{array}{l}\text { Employment Opportunities for Disabled Americans } \\
\text { Act (1986) (PL 99-463) }\end{array}$ & $\begin{array}{l}\text { - Made permanent and simplified the provisions of section } 1619 \text { allowing for special SSI } \\
\text { benefits and retention of Medicaid for disabled SSI recipients who lose Federal SSI } \\
\text { eligibility because of earnings above SGA. }\end{array}$ \\
\hline $\begin{array}{l}\text { Budget Reconciliation Act of } 1987 \\
\text { (PL 100-203) }\end{array}$ & $\begin{array}{l}\text { - Allowed payments to residents of public emergency shelters for the homeless for up to } \\
6 \text { months in a 9-month period. }\end{array}$ \\
\hline $\begin{array}{l}\text { Omnibus Budget Reconciliation Act of } 1989 \\
\text { (PL 101-239) }\end{array}$ & $\begin{array}{l}\text { - } \quad \text { Established a permanent outreach program for disabled and blind children. } \\
\text { Waived the SSI income and resource deeming rules in the case of severely disabled } \\
\text { children who were eligible for SSI while in a medical institution and who qualify for } \\
\text { Medicaid under a State home care plan. } \\
\text { - Required that property used in a person's trade or business, or in the employment of a } \\
\text { family member, be excluded when determining the equity value of a personal property. }\end{array}$ \\
\hline Sullivan v. Zebley decision (1990) & $\begin{array}{l}\text { - As a result of this decision, SSA instituted regulations in February } 1991 \text { requiring } \\
\text { children who did not meet or equal the medical listings to undergo a second stage } \\
\text { evaluation, called an "individualized functional assessment," to determine the severity } \\
\text { of their impairment and the associated limitations. }\end{array}$ \\
\hline
\end{tabular}


Table 1. (Continued)

\begin{tabular}{|c|c|}
\hline Legislation & Provisions \\
\hline $\begin{array}{l}\text { Omnibus Budget Reconciliation Act of } 1990 \\
\text { (PL 101-508) }\end{array}$ & $\begin{array}{l}\text { - Liberalized the treatment of certain income by disregarding certain expenses and } \\
\text { payments, including EITC, in determining SSI eligibility and/or benefits. } \\
\text { Authorized the exclusion of IRWEs in determining initial eligibility as well as benefit } \\
\text { amounts for both Federal and State supplemental payments. } \\
\text { - } \text { Modified section } 1619 \text {, including the authorization of (Continuing Disability Reviews) } \\
\text { CDRs for section } 1619 \text { recipients once every twelve months. } \\
\text { Required formation of procedure for a concurrent application for SSI and Food Stamp } \\
\text { Programs. } \\
\text { Required that SSA notify parents of children receiving of retroactive payments under } \\
\text { Sullivan } v \text {. Zebley that the family may be able to place the payments in a trust fund for } \\
\text { the child. } \\
\text { Extended the period during which a person applying on the basis of disability who } \\
\text { meets all other criteria and is awaiting a disability determination (presumptive period of } \\
\text { eligibility) may receive payment from } 3 \text { to } 6 \text { months. }\end{array}$ \\
\hline 1990 & - $\quad$ SGA set at $\$ 500$ \\
\hline $\begin{array}{l}\text { Revision of Mental Impairment Listings for } \\
\text { Children (1991) }\end{array}$ & $\begin{array}{l}\text { Expanded the mental impairment listings for children to include additional } \\
\text { developmental, behavioral, and emotional disorders. }\end{array}$ \\
\hline $\begin{array}{l}\text { Omnibus Budget Reconciliation Act of } 1993 \\
\text { (PL 103-66) }\end{array}$ & $\begin{array}{l}\text { Extended period of sponsor-to-alien deeming of income and resources from three to } \\
\text { five years. }\end{array}$ \\
\hline $\begin{array}{l}\text { Social Security Independence and Program } \\
\text { Improvement Act of } 1994 \text { [Alternate Title: Social } \\
\text { Security Administrative Reform Act of 1994] } \\
\text { (PL 103-296) }\end{array}$ & 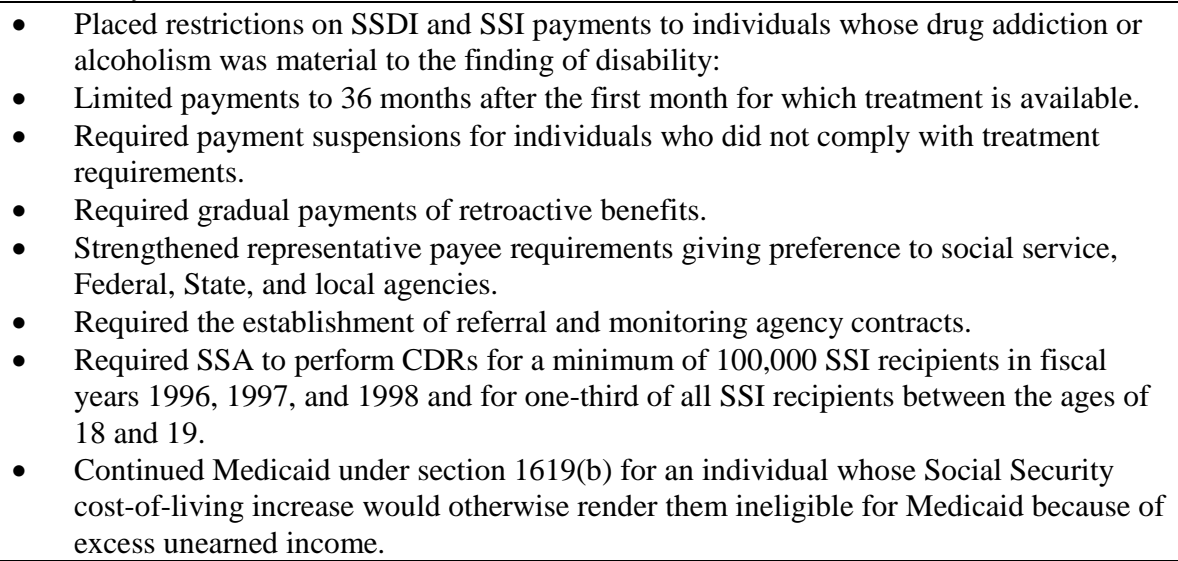 \\
\hline $\begin{array}{l}\text { Personal Responsibility and Work Opportunity } \\
\text { Reconciliation Act of } 1996\end{array}$ & $\begin{array}{l}\text { - Excluded drug and alcohol addiction as a disability impairment and tightened disability } \\
\text { criteria for children. } \\
\text { Prohibited SSI eligibility for all noncitizens, with exceptions for certain classes of } \\
\text { refugees and asylees, active duty military and veterans and their spouses and minor } \\
\text { children, and lawful permanent residents who have earned or can be credited with } 40 \\
\text { quarters of coverage for Social Security purposes. Provided a definition of which } \\
\text { noncitizens are "qualified" for SSI. }\end{array}$ \\
\hline Welfare Reform Technical Corrections Act of 1997 & $\begin{array}{l}\text { - Revised requirements of the } 1996 \text { law to continue eligibility to some classes of } \\
\text { noncitizens, and to redefine which noncitizens are "qualified" for SSI. Persons who are } \\
\text { not qualified lose eligibility as of September } 30,1998 \text {. }\end{array}$ \\
\hline $\begin{array}{l}\text { Noncitizen Benefit Clarification and Other } \\
\text { Technical Amendments Act of } 1998\end{array}$ & $\begin{array}{l}\text { - Permanently extended the eligibility of noncitizens otherwise "not qualified" under the } \\
1996 \text { and } 1997 \text { laws, but who were receiving SSI on August 22, } 1996 .\end{array}$ \\
\hline $\begin{array}{l}\text { Ticket to Work / Work Incentives Improvements } \\
\text { Act of } 1999\end{array}$ & $\begin{array}{l}\text { - } \quad \text { Expanded availability of health care coverage for working individuals with disabilities. } \\
\text { - } \quad \text { Established a Ticket to Work and Self-Sufficiency Program. }\end{array}$ \\
\hline
\end{tabular}


Table 2. SSI Eligibility Requirements in 1999

\begin{tabular}{|c|c|c|}
\hline Requirement & Definition & Exceptions/Exclusions \\
\hline Categorical: & Meet only one of these: & \\
\hline 65 or older, blind or disabled & - $\quad$ age 65 or older & \\
\hline Blind & $\begin{array}{l}\text { - } \quad \text { corrected vision of } 20 / 200 \text { or less in better eye } \\
\text { - field of vision less than } 20 \text { degrees }\end{array}$ & $\begin{array}{l}\text { Person whose visual impairment is not severe } \\
\text { enough to be considered blind may qualify under } \\
\text { the non-blind disability rules: }\end{array}$ \\
\hline Disabled & $\begin{array}{l}\text { - physical or mental impairment that keeps a } \\
\text { person from performing any "substantial" } \\
\text { work and is expected to last } 12 \text { months or } \\
\text { result in death } \\
\text { a child's impairment must result in "marked } \\
\text { and severe functional limitations" and must be } \\
\text { expected to last } 12 \text { months or result in death }\end{array}$ & $\begin{array}{l}\text { - a job that pays } \$ 500 \text { per month }(\$ 1,050 \\
\text { if blind) is generally considered substantial } \\
\text { work } \\
\text { special work incentives allow some income } \\
\text { and resources to be excluded and permit } \\
\text { payment of special cash benefits or } \\
\text { continuation of Medicaid coverage even } \\
\text { when a blind or disabled person is working }\end{array}$ \\
\hline Limited income $^{\mathrm{a}}$ & $\begin{array}{l}\text { Countable income must be: } \\
\text { - } \quad \text { below } \$ 500 \text { a month for single adult or child } \\
\text { (In states that pay SSI supplements, countable } \\
\text { income can be higher) }\end{array}$ & $\begin{array}{l}\text { Not all income counts. } \\
\text { Some exclusions are: } \\
\text { - } \quad \$ 20 \text { per month of most income } \\
\text { - } \$ 65 \text { per month of wages and one-half of } \\
\text { wages over } \$ 65 \\
\text { - food stamps } \\
\text { - } \quad \text { home energy/housing assistance } \\
\end{array}$ \\
\hline $\begin{array}{l}\text { Limited resources }^{\mathrm{a}} \\
\text { (Property and other assets a } \\
\text { person owns) }\end{array}$ & $\begin{array}{l}\text { - } \$ 2,000 \text { for single adult or child } \\
\text { - } \$ 3,000 \text { for couple (limit applies even if only } \\
\text { one member is eligible) }\end{array}$ & $\begin{array}{l}\text { Not all resources count. } \\
\text { Some exclusions are: } \\
\text { - } \quad \text { the home a person lives in } \\
\text { - a car, depending on use or value } \\
\text { burial plots for individual and immediate } \\
\text { family } \\
\text { burial funds up to } \$ 1,500 \\
\text { life insurance with face value of } 1,500 \text { or } \\
\text { less }\end{array}$ \\
\hline$\underline{\text { Citizenship/residence }}^{\mathrm{b}}$ & $\begin{array}{l}\text { resides in one of the } 50 \text { states, Washington, } \\
\text { D.C. or the Northern Mariana Islands; and } \\
\text { U.S. citizen or national; or } \\
\text { - } \quad \text { certain American Indians; or } \\
\text { lawful permanent resident with } 40 \text { work } \\
\text { credits; or } \\
\text { certain noncitizens with a military service } \\
\text { connection; or } \\
\text { certain refugee or asylee-type noncitizens } \\
\text { during the first seven years; or } \\
\text { certain noncitizens in the U.S. or receiving SSI } \\
\text { on August } 22,1996 .\end{array}$ & $\begin{array}{l}\text { Exception to residence: } \\
\text { - } \quad \text { certain children of U.S. armed forces } \\
\text { personnel stationed abroad }\end{array}$ \\
\hline \multicolumn{3}{|c|}{$\begin{array}{l}\text { a If only one member of a couple is eligible, the income and resources of both are considered in determining eligibility. } \\
\text { If a child under age } 18 \text { is living with parents, the parents' income and resources are considered. } \\
\text { b If a noncitizen has a sponsor who signed a legally unenforceable affidavit of support (INS Form I-134), the sponsor's income and resources ar } \\
\text { considered in determining eligibility and payment amount for three years following the date of lawful admission. (This rule does not apply to } \\
\text { noncitizens who become blind or disabled after legal admission for permanent residence or to noncitizens who are not lawful permanent } \\
\text { residents.) If the sponsor signed the new legally enforceable affidavit of support (INS Form I-864), the sponsor's income and resources are } \\
\text { considered until the noncitizen acquires } 40 \text { work credits or becomes a citizen. (This rule applies to noncitizens who become blind or disabled } \\
\text { after admission for permanent residence and to noncitizens who are not lawful permanent residents.) }\end{array}$} \\
\hline
\end{tabular}

Source: Social Security Administration (1999). 
Table 3. Mean Disability Allowance Rates by State, 1974-1993

State Allowance Rates ${ }^{\mathrm{a}}$

\begin{tabular}{|c|c|c|}
\hline Current State of Residence & Mean & Standard Deviation \\
\hline Alabama & 32 & 4.8 \\
\hline Arizona & 41 & 6.0 \\
\hline Arkansas & 32 & 5.6 \\
\hline California & 37 & 7.5 \\
\hline Colorado & 40 & 5.8 \\
\hline Connecticut & 45 & 8.9 \\
\hline Delaware & 48 & 4.7 \\
\hline District of Columbia & 39 & 8.0 \\
\hline Florida & 37 & 6.4 \\
\hline Georgia & 33 & 7.2 \\
\hline Illinois & 37 & 5.8 \\
\hline Indiana & 40 & 7.3 \\
\hline Iowa & 44 & 8.7 \\
\hline Kansas & 41 & 5.2 \\
\hline Kentucky & 33 & 3.8 \\
\hline Louisiana & 28 & 8.4 \\
\hline Maine & 44 & 6.1 \\
\hline Maryland & 37 & 5.1 \\
\hline Massachusetts & 44 & 7.8 \\
\hline Michigan & 37 & 6.8 \\
\hline Minnesota & 45 & 7.5 \\
\hline Mississippi & 31 & 5.9 \\
\hline Missouri & 38 & 6.8 \\
\hline Montana & 37 & 6.5 \\
\hline Nebraska & 43 & 6.1 \\
\hline Nevada & 39 & 6.9 \\
\hline New Hampshire & 42 & 5.5 \\
\hline New Jersey & 48 & 9.4 \\
\hline New Mexico & 28 & 5.3 \\
\hline New York & 41 & 9.2 \\
\hline North Carolina & 40 & 6.1 \\
\hline North Dakota & 42 & 5.9 \\
\hline Ohio & 42 & 7.8 \\
\hline Oklahoma & 33 & 6.7 \\
\hline Oregon & 37 & 6.7 \\
\hline Pennsylvania & 39 & 7.4 \\
\hline Rhode Island & 48 & 4.7 \\
\hline South Carolina & 37 & 4.7 \\
\hline South Dakota & 46 & 4.5 \\
\hline Tennessee & 35 & 6.4 \\
\hline Texas & 34 & 6.2 \\
\hline Utah & 45 & 5.9 \\
\hline Vermont & 46 & 5.3 \\
\hline Virginia & 36 & 3.4 \\
\hline Washington & 40 & 8.4 \\
\hline West Virginia & 30 & 8.3 \\
\hline Wisconsin & 46 & 6.5 \\
\hline Wyoming & 39 & 5.1 \\
\hline Total & 39 & 8.2 \\
\hline
\end{tabular}

a The mean allowance rate for a state is defined as the mean of the state's yearly initial acceptance to initial application ratio for the years 1974-1993. Allowance rates are based on SSDI applications and acceptances.

Source: Burkhauser, Butler, and Weathers (1999). 
Table 4. State Supplementation and Medicaid Eligibility in 1999, by State

\begin{tabular}{|c|c|c|c|c|c|c|c|}
\hline \multirow[b]{3}{*}{ State } & \multicolumn{4}{|c|}{ State Supplementation } & \multirow{2}{*}{\multicolumn{3}{|c|}{ Medicaid Eligibility }} \\
\hline & \multicolumn{2}{|c|}{ Type } & \multicolumn{2}{|c|}{ Eligibility for Optional } & & & \\
\hline & Mandatory & Optional & $\begin{array}{c}\text { Living } \\
\text { Independently }\end{array}$ & Other & $\begin{array}{l}\text { SSI Criteria } \\
\text { SSA } \\
\text { Administered }\end{array}$ & $\begin{array}{l}\text { SSI Criteria } \\
\text { State } \\
\text { Administered }\end{array}$ & $\begin{array}{l}\text { State Criteria } \\
\text { State } \\
\text { Administered }\end{array}$ \\
\hline Alabama & $\mathrm{e}$ & $\mathrm{a}$ & $\mathrm{d}$ & $\mathrm{d}$ & $\mathrm{a}$ & & \\
\hline Alaska & $\mathrm{a}$ & $\mathrm{a}$ & $\mathrm{a}$ & $\mathrm{a}$ & & $\mathrm{a}$ & \\
\hline Arizona & $\mathrm{a}$ & $\mathrm{a}$ & & a & $\mathrm{a}$ & & \\
\hline Arkansas & $\mathrm{a}$ & $\mathrm{f}$ & $\mathrm{f}$ & $\mathrm{f}$ & a & & \\
\hline California & $\mathrm{a}$ & $\mathrm{a}$ & a & $\mathrm{a}$ & a & & \\
\hline Colorado & $\mathrm{a}$ & $\mathrm{a}$ & $\mathrm{a}$ & a & $\mathrm{a}$ & & \\
\hline Connecticut & $\mathrm{e}$ & $\mathrm{a}$ & $\mathrm{g}$ & $\mathrm{a}$ & & & $\mathrm{a}$ \\
\hline Delaware & $\mathrm{a}$ & $\mathrm{a}$ & & $\mathrm{a}$ & $\mathrm{a}$ & & \\
\hline Florida & $\mathrm{e}$ & $\mathrm{a}$ & & $\mathrm{a}$ & $\mathrm{a}$ & & \\
\hline Georgia & a & $\mathrm{f}$ & $\mathrm{f}$ & $\mathrm{f}$ & a & & \\
\hline Hawaii & $\mathrm{a}$ & $\mathrm{a}$ & $\mathrm{a}$ & a & & & $\mathrm{a}$ \\
\hline Idaho & $\mathrm{a}$ & $\mathrm{a}$ & a & $\mathrm{a}$ & & $\mathrm{a}$ & \\
\hline Illinois & a & a & $\mathrm{g}$ & $\mathrm{d}$ & & & $\mathrm{a}$ \\
\hline Indiana & a & a & & $\mathrm{a}$ & & & $\mathrm{a}$ \\
\hline Iowa & $\mathrm{a}$ & $\mathrm{a}$ & $\mathrm{c}$ & $\mathrm{a}$ & $\mathrm{a}$ & & \\
\hline Kansas & $\mathrm{a}$ & $\mathrm{f}$ & $\mathrm{f}$ & $\mathrm{f}$ & $\mathrm{a}$ & & \\
\hline Kentucky & $\mathrm{e}$ & $\mathrm{a}$ & & $\mathrm{a}$ & $\mathrm{a}$ & & \\
\hline Louisiana & $\mathrm{a}$ & $\mathrm{a}$ & & a & $\mathrm{a}$ & & \\
\hline Maine & $\mathrm{a}$ & $\mathrm{a}$ & a & a & $\mathrm{a}$ & & \\
\hline Maryland & a & a & & $\mathrm{a}$ & a & & \\
\hline Massachusetts & $\mathrm{a}$ & $\mathrm{a}$ & a & a & a & & \\
\hline Michigan & $\mathrm{a}$ & a & a & $\mathrm{a}$ & a & & \\
\hline Minnesota & $\mathrm{a}$ & $\mathrm{a}$ & a & a & & & $\mathrm{a}$ \\
\hline Mississippi & $\mathrm{a}$ & $\mathrm{f}$ & $\mathrm{f}$ & $\mathrm{f}$ & $\mathrm{a}$ & & \\
\hline Missouri & a & a & & $\mathrm{a}$ & & & $\mathrm{a}$ \\
\hline Montana & a & $\mathrm{a}$ & & a & $\mathrm{a}$ & & \\
\hline Nebraska & $\mathrm{a}$ & a & a & a & & a & \\
\hline Nevada & $\mathrm{e}$ & a & $\mathrm{a}$ & $\mathrm{a}$ & & $\mathrm{a}$ & \\
\hline New Hampshire & $\mathrm{a}$ & $\mathrm{a}$ & $\mathrm{a}$ & $\mathrm{a}$ & & & $\mathrm{a}$ \\
\hline New Jersey & $\mathrm{a}$ & $\mathrm{a}$ & a & $\mathrm{a}$ & a & & \\
\hline New Mexico & a & a & & $\mathrm{a}$ & a & & \\
\hline New York & $\mathrm{a}$ & $\mathrm{a}$ & $\mathrm{a}$ & $\mathrm{a}$ & $\mathrm{a}$ & & \\
\hline North Carolina & $\mathrm{a}$ & a & & $\mathrm{a}$ & $\mathrm{a}$ & & \\
\hline North Dakota & $\mathrm{a}$ & $\mathrm{a}$ & $\mathrm{d}$ & $\mathrm{d}$ & & & $\mathrm{a}$ \\
\hline Ohio & a & $\mathrm{a}$ & & $\mathrm{a}$ & & & $\mathrm{a}$ \\
\hline Oklahoma & a & a & a & & & & $\mathrm{a}$ \\
\hline Oregon & $\mathrm{a}$ & $\mathrm{a}$ & $\mathrm{a}$ & $\mathrm{a}$ & & $\mathrm{a}$ & \\
\hline Pennsylvania & $\mathrm{a}$ & $\mathrm{a}$ & $\mathrm{a}$ & $\mathrm{a}$ & $\mathrm{a}$ & & \\
\hline Rhode Island & $\mathrm{e}$ & $\mathrm{a}$ & $\mathrm{a}$ & $\mathrm{a}$ & a & & \\
\hline South Carolina & $\mathrm{e}$ & a & & $\mathrm{a}$ & $\mathrm{a}$ & & \\
\hline South Dakota & $\mathrm{a}$ & $\mathrm{a}$ & $\mathrm{a}$ & $\mathrm{a}$ & $\mathrm{a}$ & & \\
\hline Tennessee & $\mathrm{a}$ & $\mathrm{f}$ & $\mathrm{f}$ & $\mathrm{f}$ & $\mathrm{a}$ & & \\
\hline Texas & $\mathrm{f}$ & $\mathrm{f}$ & $\mathrm{f}$ & $\mathrm{f}$ & $\mathrm{a}$ & & \\
\hline Utah & $\mathrm{e}$ & $\mathrm{a}$ & $\mathrm{b}$ & $\mathrm{a}$ & & $\mathrm{a}$ & \\
\hline Vermont & $\mathrm{e}$ & $\mathrm{a}$ & $\mathrm{a}$ & $\mathrm{a}$ & a & & \\
\hline Virginia & a & a & & $\mathrm{a}$ & & & $\mathrm{a}$ \\
\hline Washington & $\mathrm{a}$ & $\mathrm{a}$ & a & $\mathrm{a}$ & $\mathrm{a}$ & & \\
\hline Washington D.C. & $\mathrm{a}$ & $\mathrm{a}$ & & a & $\mathrm{a}$ & & \\
\hline West Virginia & $\mathrm{f}$ & $\mathrm{f}$ & $\mathrm{f}$ & $\mathrm{f}$ & a & & \\
\hline Wisconsin & a & a & a & $\mathrm{a}$ & a & & \\
\hline Wyoming & $\mathrm{a}$ & $\mathrm{a}$ & $\mathrm{a}$ & $\mathrm{d}$ & $\mathrm{a}$ & & \\
\hline
\end{tabular}

$a=$ program feature exists for all beneficiaries;

$\mathrm{b}=$ program feature exists for couples only;

$\mathrm{c}=$ program feature exists for blind;

$\mathrm{d}=$ information not available;

$\mathrm{e}=$ no recipients;

$\mathrm{f}=$ no program;

$\mathrm{g}=$ case by case. 
Table 5. Trends in Characteristics of SSI Recipients, 1975-1996

$\begin{array}{lllllll}1975 & 1984 & 1987 & 1990 & 1992 & 1994 & 1996\end{array}$

\begin{tabular}{|c|c|c|c|c|c|c|c|}
\hline \multicolumn{8}{|l|}{ All SSI Recipients } \\
\hline \multicolumn{8}{|l|}{ Gender } \\
\hline Male & 35.5 & 34.8 & 36.1 & 37.2 & 39.0 & 41.1 & 41.5 \\
\hline Female & 64.2 & 65.1 & 63.9 & 62.8 & 61.0 & 58.9 & 58.5 \\
\hline \multicolumn{8}{|l|}{ Race } \\
\hline White & 63.9 & 56.0 & 52.6 & 50.4 & 58.6 & 53.1 & 52.2 \\
\hline Black & 26.0 & 25.6 & 25.0 & 24.2 & 28.5 & 28.9 & 29.0 \\
\hline Other & 2.5 & 4.5 & 5.1 & 9.4 & 10.0 & 14.7 & 15.3 \\
\hline Noncitizens & na & 4.5 & 6.4 & 9.0 & 10.8 & 11.7 & 11.0 \\
\hline \multicolumn{8}{|l|}{$\begin{array}{l}\text { Disabled SSI Recipients } \\
\text { (Adults and Children) }\end{array}$} \\
\hline \multicolumn{8}{|l|}{ Qualifying Diagnosis } \\
\hline Physical & na & na & 49.0 & 47.0 & 44.7 & 42.2 & 41.3 \\
\hline Mental Retardation & na & na & 26.9 & 26.6 & 27.1 & 27.6 & 27.5 \\
\hline $\begin{array}{l}\text { Mental Impairments } \\
\text { other than Mental Retardation }\end{array}$ & na & na & 24.1 & 26.4 & 28.2 & 30.2 & 31.2 \\
\hline
\end{tabular}

na $=$ information not available.

Source: U.S. House of Representatives (1998). 
Table 6. SSI Participation Rates among Poor, 1974-1998 by Age Group

\begin{tabular}{|c|c|c|c|c|}
\hline & \multicolumn{3}{|c|}{ Take-Up Rates ${ }^{\mathrm{a}}$} & \multirow{2}{*}{$\frac{\text { Disability Prevalence }^{\mathrm{b}}}{18-64}$} \\
\hline & $65+$ & $18-64$ & $<18$ & \\
\hline 1974 & 78.5 & 14.8 & 0.7 & - \\
\hline 1975 & 75.6 & 14.8 & 1.0 & - \\
\hline 1976 & 72.3 & 15.0 & 1.2 & - \\
\hline 1977 & 74.1 & 15.3 & 1.4 & - \\
\hline 1978 & 71.3 & 15.4 & 1.7 & - \\
\hline 1979 & 61.0 & 14.4 & 1.7 & - \\
\hline 1980 & 57.4 & 12.5 & 1.6 & 20.3 \\
\hline 1981 & 55.1 & 11.0 & 1.6 & 19.2 \\
\hline 1982 & 53.6 & 9.7 & 1.4 & 17.4 \\
\hline 1983 & 55.3 & 9.6 & 1.4 & 17.5 \\
\hline 1984 & 61.2 & 10.5 & 1.6 & 19.3 \\
\hline 1985 & 58.8 & 11.3 & 1.7 & 19.0 \\
\hline 1986 & 58.0 & 12.6 & 1.9 & 19.2 \\
\hline 1987 & 56.6 & 13.4 & 2.0 & 18.8 \\
\hline 1988 & 57.6 & 13.9 & 2.0 & 18.7 \\
\hline 1989 & 60.3 & 14.8 & 2.1 & 19.6 \\
\hline 1990 & 56.3 & 14.9 & 2.3 & 19.7 \\
\hline 1991 & 55.0 & 15.0 & 2.8 & 18.9 \\
\hline 1992 & 53.5 & 15.5 & 3.6 & 19.3 \\
\hline 1993 & 56.3 & 15.9 & 4.6 & 20.4 \\
\hline 1994 & 57.9 & 17.5 & 5.5 & 21.4 \\
\hline 1995 & 63.7 & 18.9 & 6.3 & 19.9 \\
\hline 1996 & 61.0 & 19.1 & 6.6 & 20.7 \\
\hline 1997 & 60.8 & 19.7 & 6.2 & 21.3 \\
\hline 1998 & 60.0 & 20.7 & 6.6 & 21.3 \\
\hline
\end{tabular}

\footnotetext{
${ }^{a}$ Take-up rates are calculated as the number of SSI recipients divided by the number in poverty in each age group. Data are from the Social Security Administration and the Census Bureau.

${ }^{\mathrm{b}}$ Disability prevalence is calculated as the percentage of the poverty population 18-64 years of age answering "yes" to the Current Population Survey question: ADo you/Does anyone in this household) have a health problem or disability which prevent (you/them) from working or which limits the kind or amount of work (you/they) can do?@This question was not asked of children.
} 
Table 7. Prevalence of Multiple Program Participation by SSI Recipients, 1984-1995

\begin{tabular}{lrrrrrr} 
& 1984 & 1987 & 1990 & 1992 & 1994 & 1995 \\
\hline Food Stamps & 46.5 & 39.7 & 41.3 & 46.2 & 50.1 & 50.0 \\
Women, Infants, and Children (WIC) & 2.5 & 2.5 & 3.0 & 4.3 & 5.4 & 5.6 \\
Free or Reduced Price Meals & 12.7 & 11.9 & 15.3 & 18.2 & 23.8 & 24.9 \\
Public or Subsidized Rental Housing & 21.6 & 20.0 & 21.4 & 23.8 & 24.9 & 24.1 \\
Medicaid & 100.0 & 99.6 & 99.7 & 99.8 & 100.0 & 100.0 \\
VA Compensation or Pensions & 4.7 & 7.7 & 5.7 & 4.0 & 3.9 & 3.6 \\
Social Security Benefits & 49.6 & 48.9 & 45.9 & 41.3 & 39.1 & 37.9 \\
\hline
\end{tabular}

Source: U.S. House of Representatives (1998). 
Table 8. Labor Force Participation and Transfer Receipt among People with Disabilities

before Passage of the Americans with Disabilities Act of 1990, Using PSID (1989) and SIPP (1990) Data (in 1991 dollars)

PSID

$\operatorname{SIPP}^{\mathrm{a}}$

\begin{tabular}{cccccccc}
\hline \multicolumn{2}{c}{ Men } & \multicolumn{2}{c}{ Women } & \multicolumn{2}{c}{ Men } & \multicolumn{2}{c}{ Women } \\
\hline $\begin{array}{c}\text { With } \\
\text { Disability }^{\mathrm{b}}\end{array}$ & $\begin{array}{c}\text { Without } \\
\text { Disability }\end{array}$ & $\begin{array}{c}\text { With } \\
\text { Disability }^{\mathrm{b}}\end{array}$ & $\begin{array}{c}\text { Without } \\
\text { Disability }\end{array}$ & $\begin{array}{c}\text { With } \\
\text { Disability }^{\mathrm{c}}\end{array}$ & $\begin{array}{c}\text { Without } \\
\text { Disability }^{2}\end{array}$ & $\begin{array}{c}\text { With } \\
\text { Disability }^{\mathrm{c}}\end{array}$ & $\begin{array}{c}\text { Without } \\
\text { Disability }^{2}\end{array}$ \\
\hline 9.2 & 90.8 & 10.6 & 89.4 & 9.8 & 90.2 & 9.8 & 90.2 \\
65.0 & 97.5 & 52.1 & 80.5 & 54.8 & 96.5 & 43.6 & 79.9 \\
38.0 & 2.9 & 25.8 & 4.4 & 43.7 & 5.6 & 40.7 & 8.2 \\
& & & & & & & \\
43.0 & 83.6 & 18.7 & 42.5 & 41.1 & 86.1 & 26.2 & 55.7 \\
15.9 & 2.5 & 8.7 & 3.3 & & & & \\
22.0 & 13.9 & 33.4 & 38.0 & 13.6 & 10.4 & 16.4 & 24.3 \\
35.0 & 2.5 & 47.9 & 19.5 & 45.2 & 3.5 & 56.4 & 20.1 \\
68.0 & 9.2 & 42.8 & 6.4 & 74.4 & 24.4 & 59.3 & 18.2 \\
\hline
\end{tabular}

${ }^{a}$ Because rotation groups start at different calendar times, the yearly time period is sometime between October 1990 and 1992.

${ }^{\mathrm{b}}$ People who reported a physical or nervous condition that limits the type of work or the amount of work they could do in both 1988 and 1989.

${ }^{c}$ Persons who report a health limitation or receipt of SSDI in both wave 3 and wave 6 of the 1990 Full Panel SIPP.

${ }^{\mathrm{d}}$ Population is limited to those aged 25 to 61 who were either family heads or spouses and were so in both the 1988 and 1989 PSID surveys or persons aged 25 to

61 in both wave 3 and wave 6 of SIPP.

${ }^{\mathrm{e}}$ Public transfers not only include transfers targeted for people with disabilites: Social Security Disability Insurance, Supplemental Security Income, Veterans

Disability Benefits and Workers=Compensation, but also Unemployment Insurance, Aid to Families with Dependent Children and Food Stamps.

${ }^{g}$ People who worked at least 1,820 hours in 1988 ( 35 hours per week).

${ }^{\text {h }}$ People who worked at least 52 hours but no more than 1,820 hours in 1988.

${ }^{\mathrm{i}}$ People who worked less than 52 hours in 1988.

Source: Burkhauser and Daly (1996) and Wittenburg (1997). 
Table 9. SSI Allowance Rates for Adults Age 18-64, 1974-1998

\begin{tabular}{|c|c|c|c|}
\hline & Allowance Rate (percentage) & Population (thousands) & Yearly Percent Change \\
\hline 1974 & 47.8 & 1,503 & \\
\hline 1975 & 52.6 & 1,699 & 13.0 \\
\hline 1976 & 47.1 & 1,714 & 0.9 \\
\hline 1977 & 42.2 & 1,737 & 1.3 \\
\hline 1978 & 36.4 & 1,747 & 0.6 \\
\hline 1979 & 31.5 & 1,727 & -1.1 \\
\hline 1980 & 29.5 & 1,731 & 0.2 \\
\hline 1981 & 29.5 & 1,703 & -1.6 \\
\hline 1982 & 26.6 & 1,655 & -2.8 \\
\hline 1983 & 32.2 & 1,700 & 2.7 \\
\hline 1984 & 38.2 & 1,780 & 4.7 \\
\hline 1985 & 32.0 & 1,879 & 5.6 \\
\hline 1986 & 36.8 & 2,010 & 6.7 \\
\hline 1987 & 36.2 & 2,119 & 5.4 \\
\hline 1988 & 37.1 & 2,203 & 4.0 \\
\hline 1989 & 39.5 & 2,302 & 4.5 \\
\hline 1990 & 40.5 & 2,450 & 6.4 \\
\hline 1991 & 39.4 & 2,642 & 7.8 \\
\hline 1992 & 44.5 & 2,910 & 10.1 \\
\hline 1993 & 41.1 & 3,148 & 8.2 \\
\hline 1994 & 39.4 & 3,335 & 5.9 \\
\hline 1995 & 42.5 & 3,482 & 4.4 \\
\hline 1996 & 41.6 & 3,569 & 2.5 \\
\hline 1997 & 40.8 & 3,562 & -0.2 \\
\hline 1998 & 42.9 & 3,646 & 2.4 \\
\hline
\end{tabular}

Source: Authors=alculations from SSA data (Annual Statistical Supplement, various years). 
Table 10. AFDC and SSI Benefit Levels for Maryland and Connecticut, 1990 and $1994^{\mathrm{a}}$

\begin{tabular}{cccccc} 
State & $\begin{array}{c}\text { AFDC benefit } \\
\text { for family } \\
\text { of three } \\
(1)\end{array}$ & $\begin{array}{c}\text { AFDC benefit } \\
\text { for family } \\
\text { of two } \\
(2)\end{array}$ & $\begin{array}{c}\text { Difference } \\
{[(1)-(2)]} \\
(3)\end{array}$ & $\begin{array}{c}\text { Federal } \\
\text { SSI benefit } \\
(4)\end{array}$ & $\begin{array}{c}\text { Net SSI benefit } \\
{[(4)-(3)]} \\
(5)\end{array}$ \\
\hline $\begin{array}{c}\text { Maryland } \\
1990\end{array}$ & $\$ 4872$ & $\$ 3804$ & $\$ 1068$ & $\$ 4632$ & $\$ 3564$ \\
1994 & $\$ 4392$ & $\$ 3432$ & $\$ 960$ & $\$ 5352$ & $\$ 4392$ \\
Connecticut & & & & & \\
1990 & $\$ 6660$ & $\$ 5424$ & $\$ 1236$ & $\$ 4632$ & $\$ 3396$ \\
1994 & $\$ 8160$ & $\$ 6588$ & $\$ 1572$ & $\$ 5352$ & $\$ 3780$ \\
\hline
\end{tabular}

${ }^{a}$ All benefit levels are state maximums, assuming the family earns no countable income. Both Maryland and Connecticut did not provide SSI state supplements to children during this time period.

Source: Kubik (1999). 
Table 11. Income Receipt from Various Sources Among the Poor, 1980-1998 ${ }^{\mathrm{a}}$ by Age Group

\begin{tabular}{|c|c|c|c|c|c|c|c|c|c|}
\hline & \multicolumn{3}{|c|}{ SSI } & \multicolumn{3}{|c|}{ Other Public Assistance } & \multicolumn{2}{|c|}{ Labor Market } & \multirow[b]{2}{*}{$65+$} \\
\hline & $<18$ & $18-64$ & $65+$ & $<18$ & $18-64$ & $65+$ & $<18$ & $18-64$ & \\
\hline 1980 & 6.8 & 9.8 & 22.3 & 46.2 & 27.6 & 5.0 & 64.4 & 62.3 & 10.2 \\
\hline 1981 & 5.9 & 9.2 & 21.0 & 45.8 & 26.5 & 3.2 & 65.3 & 63.7 & 9.3 \\
\hline 1982 & 5.4 & 8.5 & 19.9 & 44.5 & 27.7 & 3.2 & 63.7 & 62.4 & 10.0 \\
\hline 1983 & 5.6 & 8.5 & 20.8 & 45.2 & 27.8 & 2.6 & 62.4 & 62.6 & 9.2 \\
\hline 1984 & 5.4 & 9.0 & 23.2 & 47.2 & 29.2 & 3.3 & 61.7 & 61.9 & 9.3 \\
\hline 1985 & 5.8 & 9.0 & 20.5 & 47.9 & 27.9 & 3.1 & 63.2 & 62.8 & 8.5 \\
\hline 1986 & 5.5 & 8.6 & 18.0 & 49.5 & 28.7 & 3.4 & 61.4 & 61.9 & 9.3 \\
\hline 1987 & 7.2 & 10.6 & 20.2 & 49.4 & 30.7 & 3.9 & 60.3 & 60.2 & 8.9 \\
\hline 1988 & 5.9 & 10.1 & 19.7 & 48.5 & 28.9 & 3.1 & 63.1 & 61.7 & 9.5 \\
\hline 1989 & 8.0 & 11.8 & 22.3 & 46.7 & 29.2 & 3.6 & 62.7 & 62.3 & 9.5 \\
\hline 1990 & 7.4 & 12.0 & 21.1 & 49.7 & 30.7 & 3.9 & 64.4 & 62.0 & 9.9 \\
\hline 1991 & 7.3 & 11.9 & 20.5 & 52.2 & 31.9 & 4.1 & 61.3 & 62.4 & 9.5 \\
\hline 1992 & 8.6 & 12.8 & 19.1 & 50.5 & 30.4 & 3.3 & 62.2 & 61.9 & 8.6 \\
\hline 1993 & 9.9 & 13.2 & 17.7 & 49.8 & 29.7 & 3.5 & 60.7 & 61.3 & 9.2 \\
\hline 1994 & 10.6 & 13.5 & 19.2 & 47.6 & 27.9 & 3.2 & 64.3 & 61.7 & 8.2 \\
\hline 1995 & 10.7 & 13.9 & 17.7 & 45.1 & 26.0 & 2.5 & 66.7 & 63.2 & 7.7 \\
\hline 1996 & 11.6 & 15.1 & 18.2 & 41.5 & 24.1 & 2.3 & 68.8 & 63.2 & 8.7 \\
\hline 1997 & 9.8 & 13.9 & 18.0 & 38.4 & 21.5 & 2.5 & 70.1 & 63.8 & 8.5 \\
\hline 1998 & 10.6 & 14.5 & 16.3 & 32.0 & 17.0 & 2.0 & 73.8 & 63.0 & 9.3 \\
\hline
\end{tabular}

\footnotetext{
${ }^{a}$ Percentages reflect the share of individuals in each age group living in households receiving income from each of the three sources.
}

Source: Authors' calculations from CPS March Demographic Supplements, 1981-1999. 
Figure 1. SSI Application Process and Eligibility Criteria ${ }^{\mathrm{a}}$

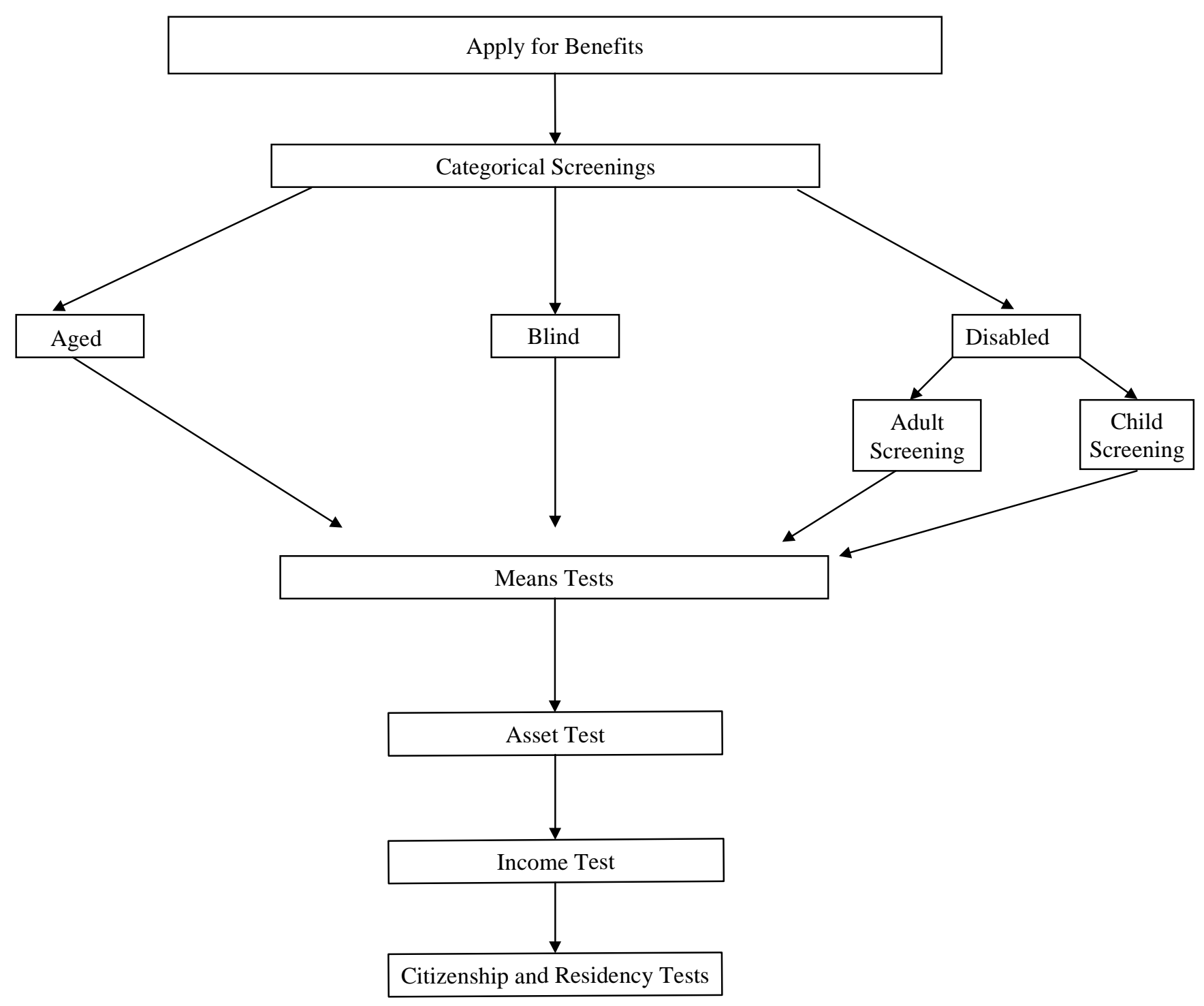

${ }^{a}$ See Table 2 for a complete description of the eligibility criteria at each stage of the application process.

Source: Created by the authors. 
Figure 2. SSA Initial Disability Determinations

Sequential Decisionmaking Process and Outcomes of Decisions on Initial SSDI Applications, 1994

(1) Is the applicant engaging in substantial gainful activity?

(earning more than $\$ 500$ per month)

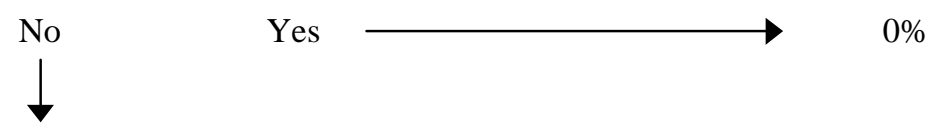

(2) Does the applicant have a severe impairment (combinations of impairments) that limits basic work activities?

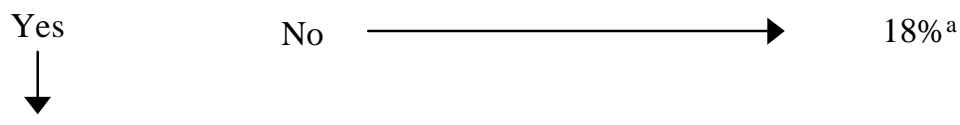

Is the impairment expected to last 12 months or result in death?

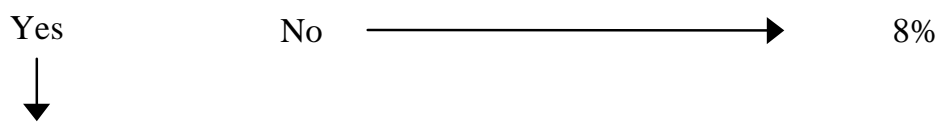

(3a) Does the impairment(s) meet the medical listings?

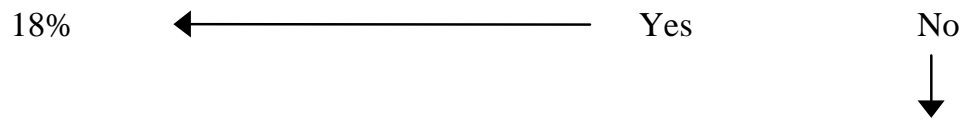

(3a) Does the impairment(s) equal the medical listings?

$3 \%$

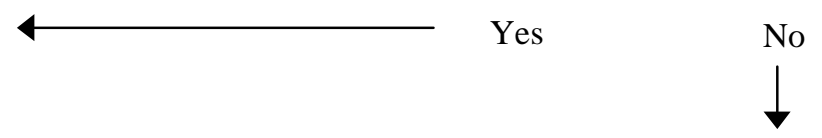

(Assess residual functional capacity)

(4) Does the impairment(s) prevent doing past work?
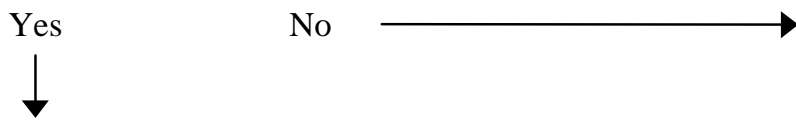

(Consider applicant's age, education and work experience)

(5) Does the impairment(s) prevent any other work that exists in the national economy?
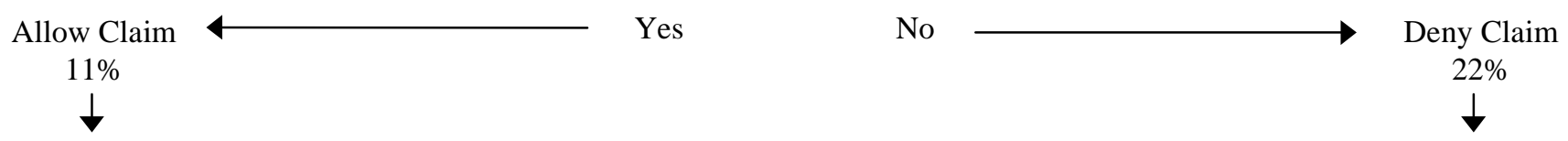

Allowances as part of

Denials as part of initial applications initial applications $32 \%$ $68 \%$

a This response includes 5 percent of claims that were denied because the applicant failed to cooperate in obtaining evidence needed for the claim. The other 13 percent were denied for "impairment not severe."

Source: Mashaw and Reno (1996). 
Figure 3. Sequential Initial Disability Determination Process For Children

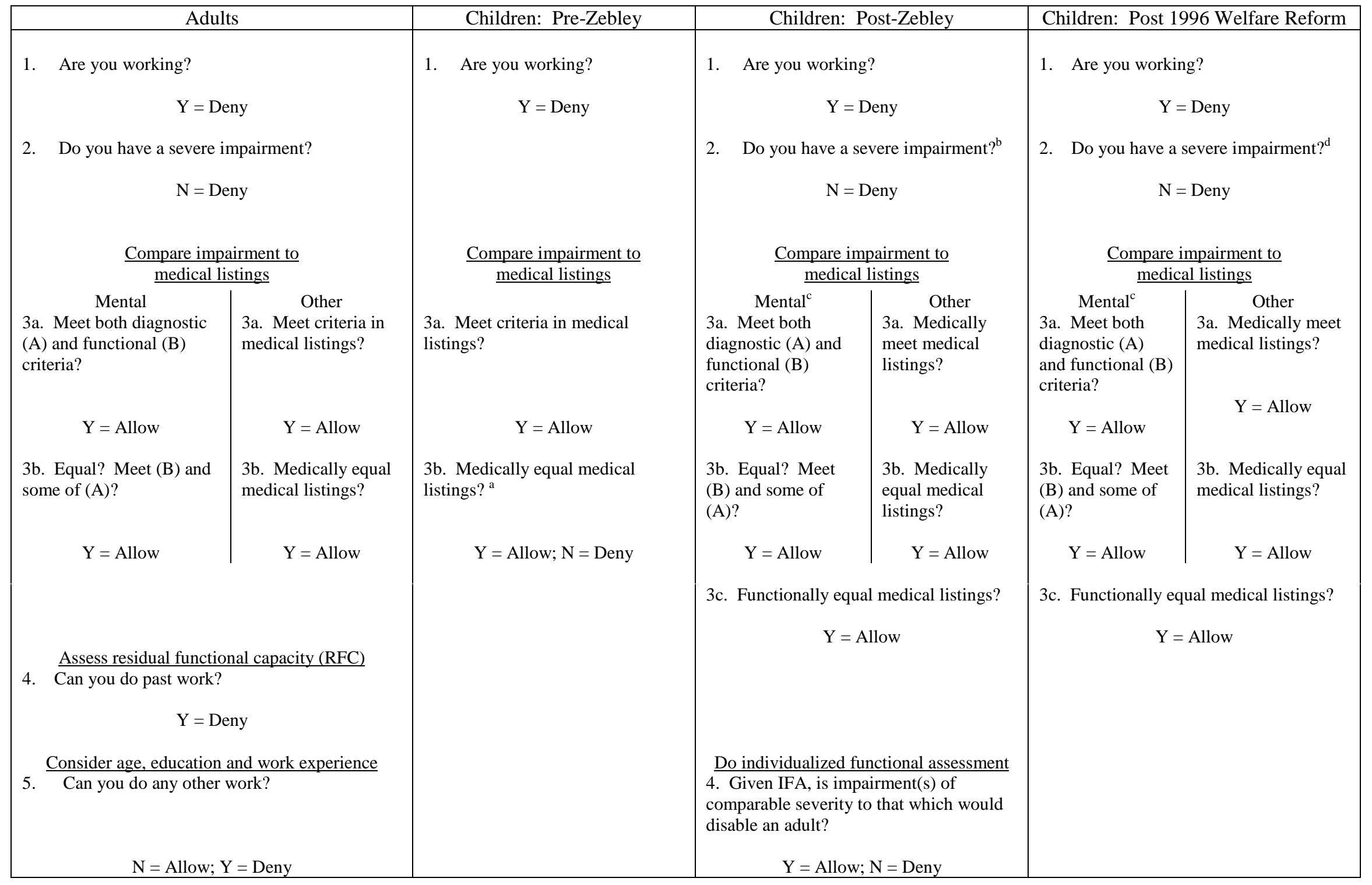

${ }^{a}$ Before 1990, SSA policy in SS Ruling 83-19 explicitly prohibited using an overall functional assessment to find that a claimant's impairment equalled the medical listings. A claimant with multiple impairments could meet or equal the listings only if at least one impairment, alone, met or medically equalled a specific listing.

${ }^{\mathrm{b}}$ A medically determinable physical or mental impairment of comparable severity to one meeting adult definition.

${ }^{\mathrm{c}}$ The childhood mental disorders listings were modified in 1990 to include functional criteria similar to those put in the adult listings in 1985.

${ }^{\mathrm{d}}$ A medically determinable physical or mental impairment which results in marked and severe functional limitation.

Source: Created by authors. 
Figure 4. SSI Program Growth, 1974-1998

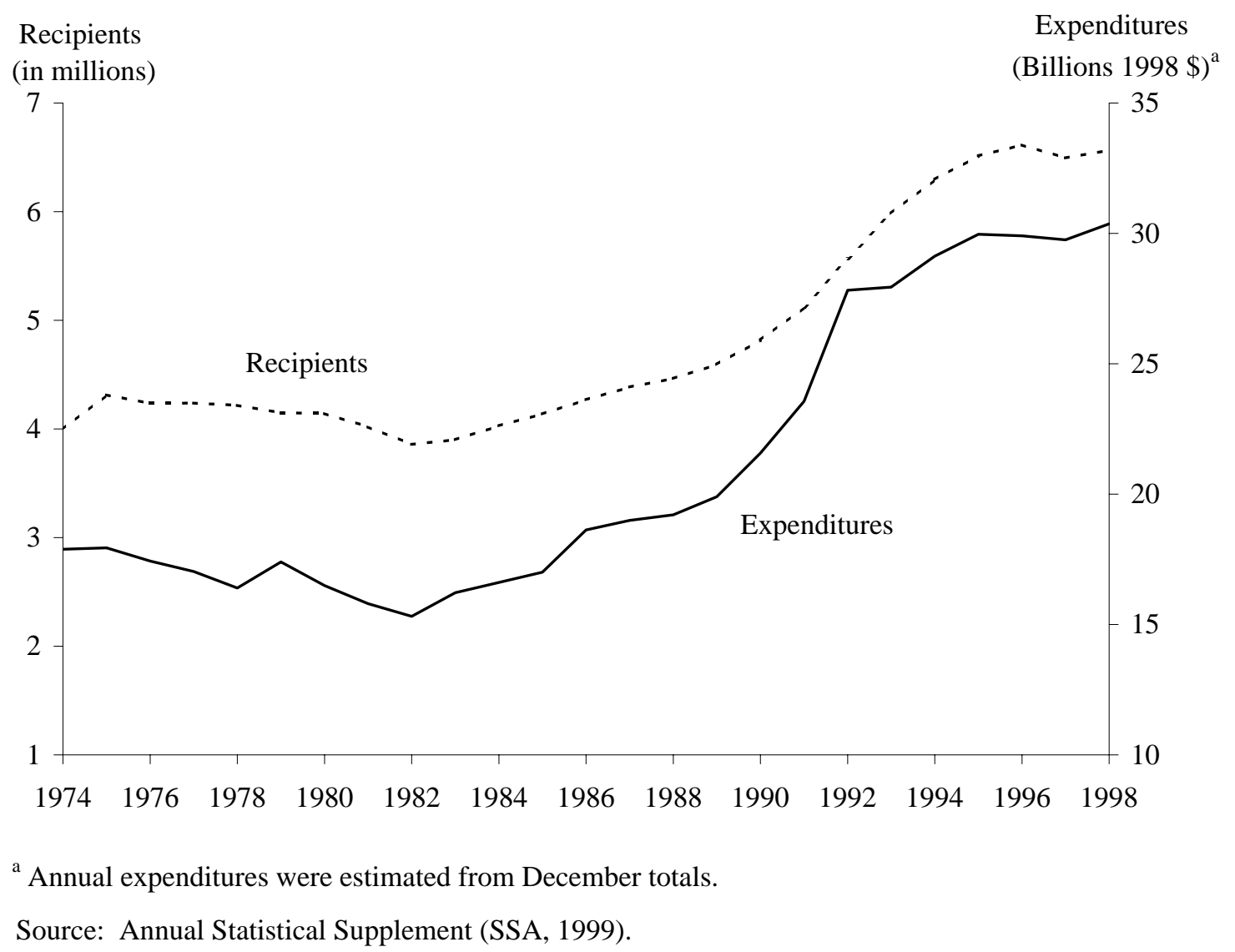


Figure 5. SSI Caseloads by Age Group, 1974-1998

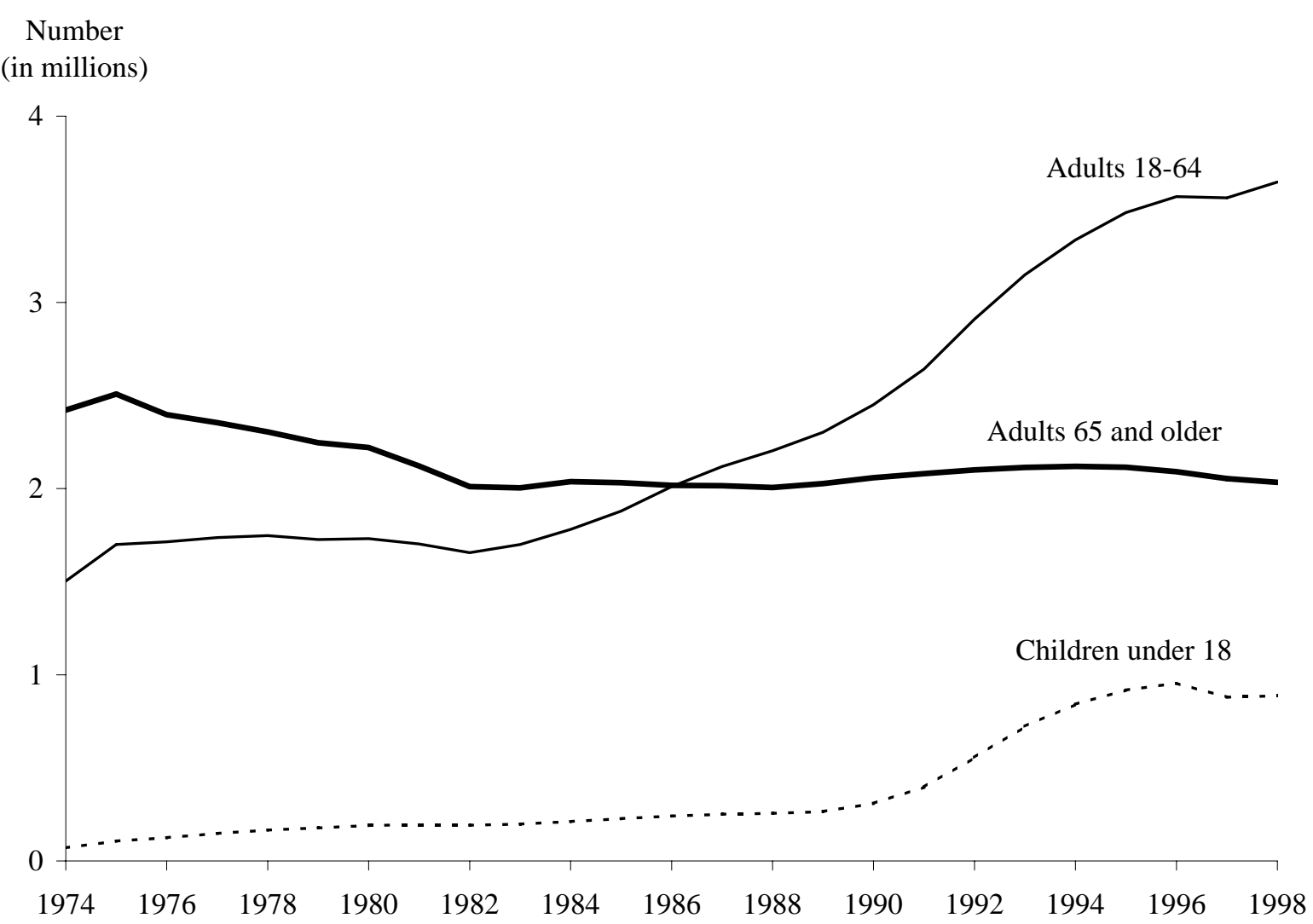

Source: Annual Statistical Supplement, SSA various years. 
Figure 6. Marginal Tax Rates on Labor Earnings and Net Income for a Single Person Receiving Medicaid, SSI, and Food Stamps in 1994

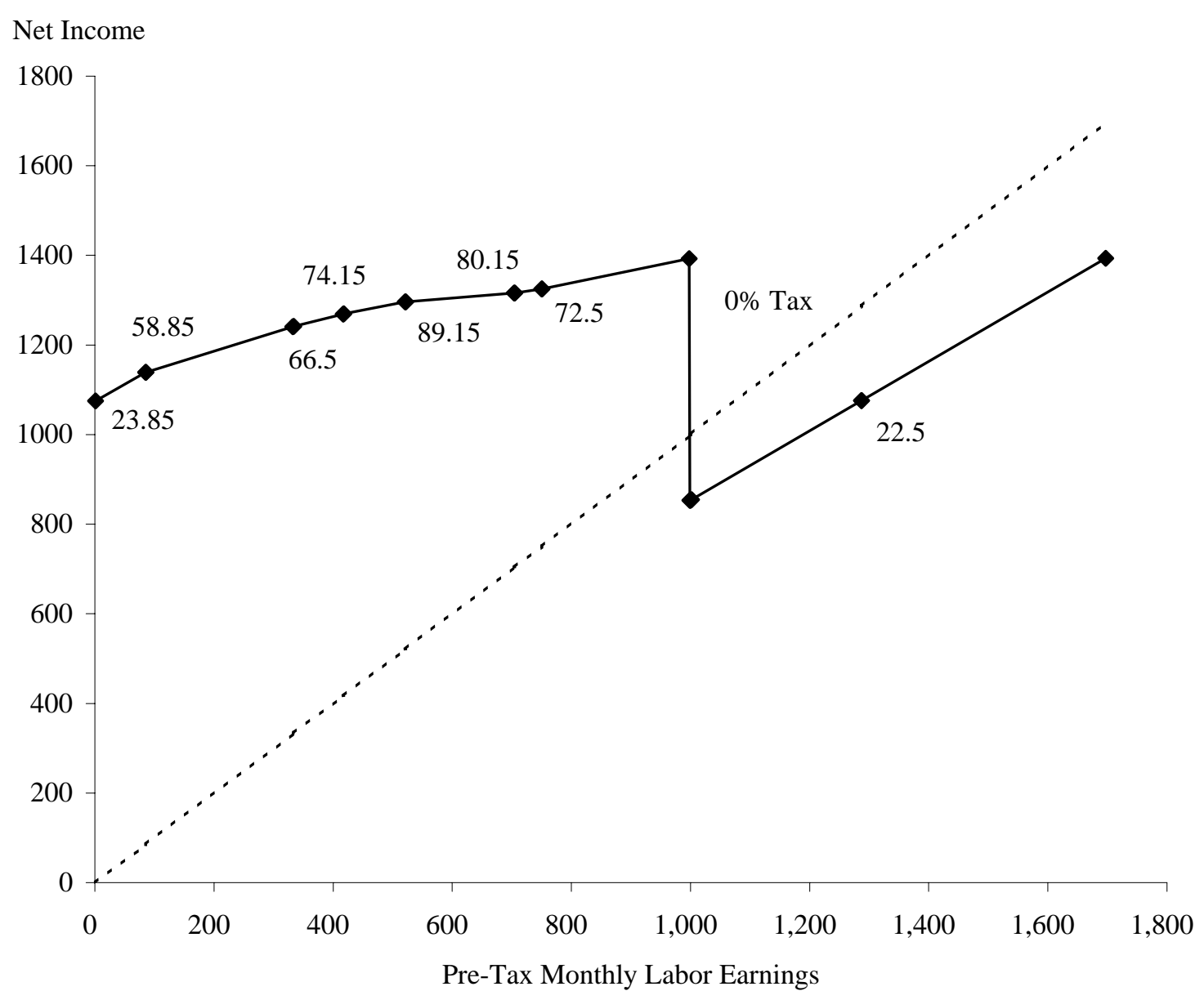

Source: Burkhauser and Wittenburg (1996). 
Figure 7. Budget Constraints with Different Marginal Tax Rates

(BC: Marginal Tax Rate $=100$ percent, BD: Marginal Tax Rate $=50$ percent)

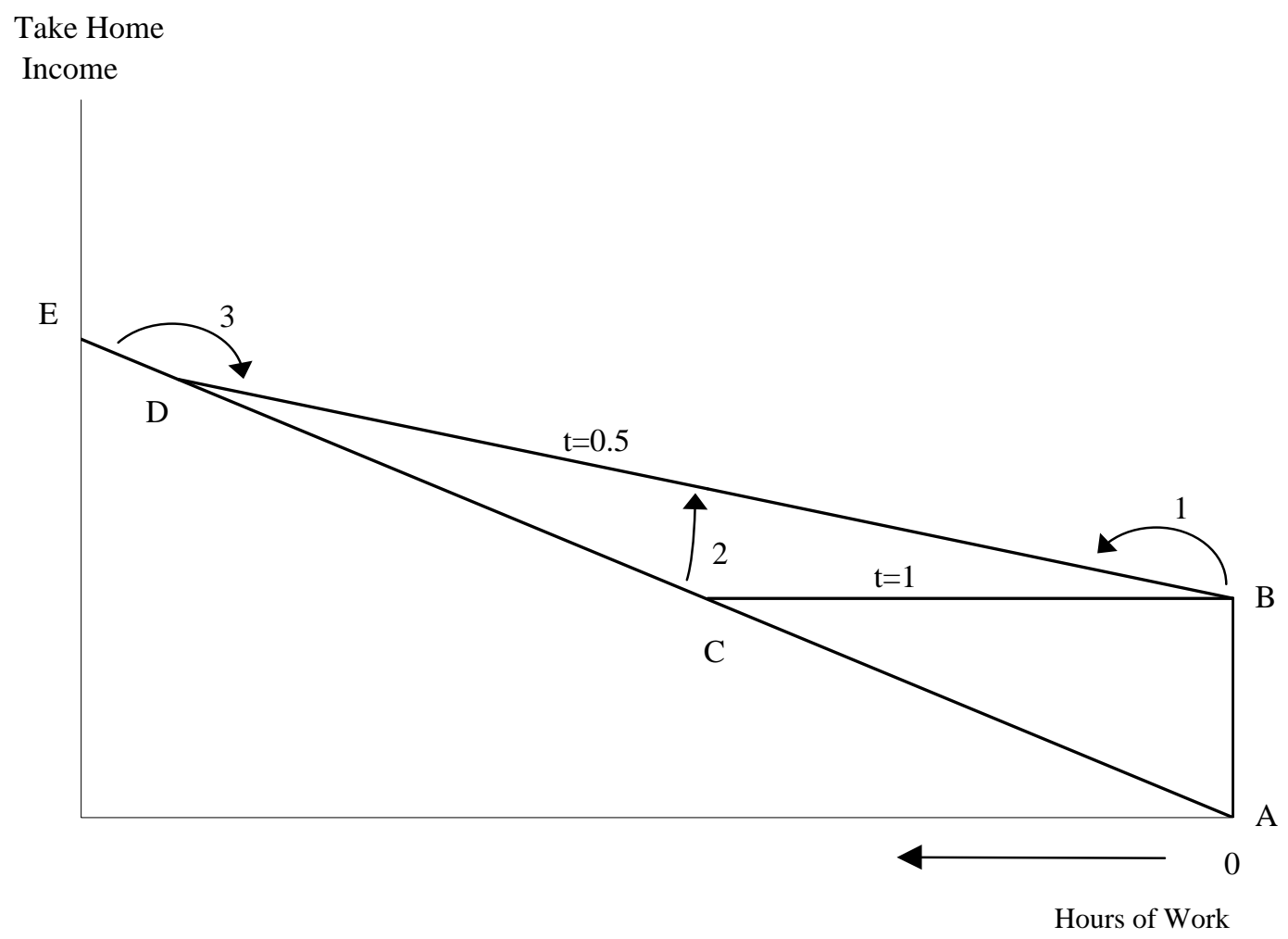

Source: Hoynes and Moffitt (1996). 
Figure 8. Applications and Awards Among Population 18-64

(per 1000 in population)

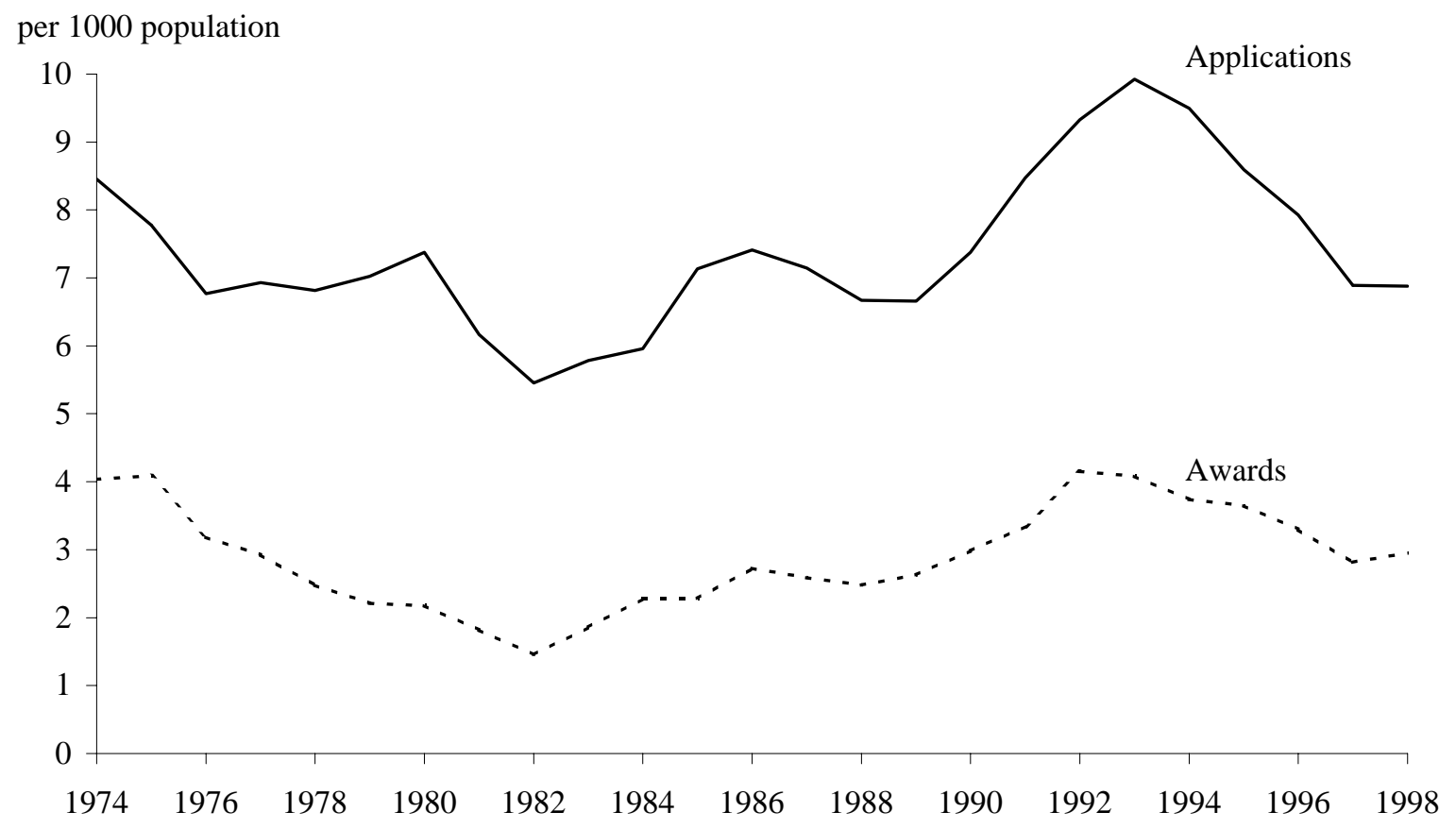

Source: Annual Statistical Supplement, SSA various years. 